\title{
Money-Back Guarantee, Dual Money-Back Guarantee, and 020 Strategy in a Manufacturer's Dual-Channel Supply Chain
}

\author{
Jiqiong Liu $\mathbb{D},{ }^{1,2,3}$ Minglun Ren, ${ }^{1}$ Aifeng Yang, ${ }^{1}$ and Shuai Feng $\mathbb{D}^{1,2,3}$ \\ ${ }^{1}$ School of Management, Hefei University of Technology, Hefei 230009, China \\ ${ }^{2}$ School of Business, Fuyang Normal University, Fuyang 236037, China \\ ${ }^{3}$ Anhui Provincial Key Laboratory of Regional Logistics Planning and Modern Logistics Engineering, Fuyang 236037, China \\ Correspondence should be addressed to Shuai Feng; fengshuai@mail.hfut.edu.cn
}

Received 29 July 2019; Revised 26 January 2020; Accepted 29 January 2020; Published 27 February 2020

Academic Editor: Neale R. Smith

Copyright ( 2020 Jiqiong Liu et al. This is an open access article distributed under the Creative Commons Attribution License, which permits unrestricted use, distribution, and reproduction in any medium, provided the original work is properly cited.

Return services are increasingly valued by manufacturers, retailers, and customers. In many countries, an offer of money-back guarantee (MBG) is legally binding. In this paper, we discuss how a retailer and manufacturer with a direct channel should choose single or dual MBG and pricing strategies. We identify the conditions under which a retailer or manufacturer should choose a return strategy and show that the handling return loss and the customer return cost in each channel are critical factors that should be considered by the retailer and manufacturer when choosing a return strategy. In addition, the retailer should cooperate with the manufacturer to establish an offline-to-online $(\mathrm{O} 2 \mathrm{O})$ omnichannel to fully benefit from the convenience and advantages of the retail channel. We find that the adoption of the $\mathrm{O} 2 \mathrm{O}$ strategy by the retailer in its retail channel always generates profits, while the manufacturer may implement the $\mathrm{O} 2 \mathrm{O}$ strategy in its direct channel when the profit from the Internet service is higher than a threshold. Additionally, the impact of various strategies on pricing, market share, and profits is discussed.

\section{Introduction}

During the recent Tmall "Double Eleven" shopping festival in 2018 , a single day's turnover reached $\$ 30.835$ billion. Faced with the temptation of sales through online channels and the rapid development of the e-commerce market, increasing numbers of manufacturers have begun to transform and upgrade. Based on the existing traditional retail channel, they open online direct sales channels and directly sell products to customers, forming a dual channel. This sales model generates more market share and economic profit. For example, an increasing number of PC manufacturers, such as Hewlett-Packard, Dell, and Toshiba, are opening online direct sales channels while selling products through retail partners, such as Walmart and CompUSA [1]. For example, to compensate for the gap in online sales in Southeast Asia, Apple joined forces with Lazada, Southeast Asia's largest shopping site, in 2017 to announce that it would launch online direct sales in several Southeast Asia countries, some of which are the first to have official direct online sales services from Apple [2].
Customer service and pricing are among the most important marketing strategies enabling sellers to maintain market competitiveness [3]. Given the popularity of product returns, sellers have begun to focus on creating a good return experience as a way to compete in customer service and offer loose return strategies. Return strategies (policies) usually include a full refund strategy (e.g., money-back guarantee, $M B G$ ) and a partial refund strategy (i.e., retailers allowing returns but deducting a corresponding refund fee, thereby returning only a partial refund of the purchase price to the customers, which is commonly observed in the unsubscribe refund of tickets). McWilliams [4] found that in the dualchannel environment, as a relaxed return strategy, MBG is widely available in both the traditional brick-and-mortar retail channel (we refer to this channel simply as the "retail" channel) and the online direct sales channel (we refer to this channel simply as the "direct" channel). McWilliams and Gerstner [5] found that $87 \%$ of 47 large stores in the United States have implemented a full MBG strategy, while $13 \%$ offer a partial refund strategy such that the retailer demands a refund fee and returns only a partial refund of the purchase 
price to the customers. McWilliams [4] found that all top 10 online clothing retailers on the Top 500 list on the Internet Retailers website and 16 high-selling brick-and-mortar retailers offer MBG. MBG is very popular with customers because this guarantee allows for the return of unsatisfactory products with a full refund [6,7]. In addition, MBG can reduce the perception of risk and stimulate the desire to purchase, thereby enhancing customers' willingness to purchase and increasing their willingness to pay [8].

From a retailer or manufacturer's perspective, although MBG increases customer satisfaction and stimulates sales, it can also result in a large volume of product returns and high associated processing costs, which could affect the profitability of retailers and manufacturers $[1,9]$. The average return rate via traditional retail channels is $8 \%$ [10], but the return rate of e-commerce network sales usually ranges between $20 \%$ and 40 [11]. In the fashion and apparel industry, the return rate can be as high as 74\% [12]. At such high return rates, processing returns is very expensive for retailers and manufacturers. It is estimated that US manufacturers and retailers spend more than 100 billion US dollars per year on processing returns and related logistics [13]. Each manufacturer and retailer lost an average of $3.8 \%$ of revenue [14].

In practice, some manufacturers and retailers choose to tighten their free return strategies to reduce and limit the costs of processing returns and related reverse costs [15], and some have not even implemented a return strategy [16]. However, in some cases, the manufacturer also provides a more lenient return service to the retailer and does not allow the retailer to resell the returned product. For example, both Hewlett-Packard and Bosch require retailers to return any returned product to their manufactures' return centers [17]. Therefore, how should one launch MBG services? Should it only do so for customers? Or should it be more relaxed and available not only to the customers but also to the retailers in the form of dual MBG (DMBG) services, that is, where manufacturers also provide MBG services to retailers? Should it not provide return services? How do manufacturers and retailers choose which MBG services to offer? What factors influence the choice of return strategy? This series of questions remains open and deserves attention.

To reduce the return rate, retailers can also exploit the convenience and advantages of their retail channels-display and experience. Retailers can cooperate with manufacturers to integrate channels and implement the increasingly popular omnichannel offline-to-online (O2O) strategy. With the omnichannel $\mathrm{O} 2 \mathrm{O}$ strategy, the offline retail channel and the online direct sales channel form an omnichannel, and the offline retail channel provides product line display and experience services. To prevent channel conflicts and customer service free-riding behavior, the omnichannel generally implements a uniform pricing strategy. The $\mathrm{O} 2 \mathrm{O}$ omnichannel strategy based on uniform pricing has been implemented in the electronics industry, for example, by Apple, Huawei, and Mi, which have opened online direct sales channels and retail experience stores (retail channels) to provide consumers with offline product line display and experience. The offline channel is channeled to the online channel to introduce customers to a wider range of product lines and services, which will encourage the development of brand fans and the repurchase of other products and services. However, what is the impact of the uniform pricing based $\mathrm{O} 2 \mathrm{O}$ omnichannel strategy on product return rates? How does the $\mathrm{O} 2 \mathrm{O}$ strategy affect consumer purchasing behavior and how does it affect the optimal pricing decisions of manufacturers and retailers? This series of questions also attracts our attention and is worth studying.

In this paper, in the context of a retailer and manufacturer with a direct channel who face customer returns and pricing issues, we examine the commonly adopted MBG, newly emerged DMBG, and popular $\mathrm{O} 2 \mathrm{O}$ omnichannel strategies. Specifically, we study the following.

(1) How should a retailer with a retail channel and a manufacturer with a direct channel choose their return strategy? Should the widely adopted MBG or the more relaxed DMBG strategy be implemented?

(2) How do the MBG and DMBG strategies affect the pricing, market share, and profits of the retailer and manufacturer in the dual channel?

(3) How does the implementation of the $\mathrm{O} 2 \mathrm{O}$ omnichannel strategy affect the retailer and manufacturer's choice of return strategies, their market shares, and their optimal pricing decisions? How do these factors in turn affect consumer purchasing behavior?

(4) Should the retailer and manufacturer achieve channel cooperation? What is the optimal choice between the $\mathrm{O} 2 \mathrm{O}$ strategy and the MBG/DMBG strategy?

To address these questions, we consider a dual-channel supply chain that includes a retailer and a Stackelberg manufacturer with a direct channel. We use a game theory model to discuss how the retailer and manufacturer determine customer return strategies (the MBG or DMBG strategy) and pricing strategies (based on a nonuniform pricing $\mathrm{MBG} / \mathrm{DMBG}$ strategy or an $\mathrm{O} 2 \mathrm{O}$ omnichannel strategy based on uniform pricing). How do the different strategies affect the competition between the two channels?

We show that the return loss and customer return cost in the purchasing channel are important factors that the retailer and manufacturer should consider when choosing a return strategy. Specifically, for a retailer, the retailer can set the return strategy based on the level of return loss and the customer return cost based on its retail channel. We found that if the retailer and manufacturer cannot achieve channel cooperation and implement nonuniform pricing, as long as the return loss and the customer return cost in the retail channel are less than those in the direct channel, the retailer should provide MBG instead of DMBG. However, the retailer tends to choose the $\mathrm{O} 2 \mathrm{O}$ strategy if it collaborates with the manufacturer to build an omnichannel and implement uniform pricing.

Interestingly, for a manufacturer, when the net residual value of satisfaction in the direct channel is positive, 
although the DMBG return strategy can effectively improve the manufacturer's direct profit, the manufacturer is still willing to provide an MBG return strategy because the manufacturer is more reliant on retailers to sell products, thereby obtaining more wholesale profit. However, notably, the manufacturer also benefits from DMBG, which not only reduces the pressure on the retailer to address customer returns and thus alleviates channel conflicts but also increases the market shares and profits of direct channels. Therefore, during the initial period after a manufacturer opens a direct channel, the manufacturer can consider the implementation of a DMBG return strategy, thus alleviating channel conflicts and rapidly increasing the market share of the direct channel.

Furthermore, we determined the conditions under which the manufacturer would be willing to work with the retailer to build an omnichannel and implement an $\mathrm{O} 2 \mathrm{O}$ strategy with uniform pricing, namely, when the profit conversion rate of the Internet service exceeds a certain threshold, and the offline channel can fully drain the online channel; in this case, the manufacturer would be willing to sacrifice more wholesale profit to implement an $\mathrm{O} 2 \mathrm{O}$ strategy.

Although there is a substantial literature on the dualchannel environment, less attention has been devoted to the joint consideration of a single or dual MBG return strategy and $\mathrm{O} 2 \mathrm{O}$ strategy, especially not to all three simultaneously. This paper extends the existing literature and practice in this direction. First, we expand the literature on the MBG and $\mathrm{O} 2 \mathrm{O}$ strategy in a dual-channel environment. In previous research on dual-channel MBG, the dual-channel structure considered is a retailer that not only operates a traditional retail channel but also opens an online channel, that is, operates two channels (e.g., $[3,4,18])$. However, especially for large brands (such as Apple, Samsung, and Dell), the manufacturers often open the online channel, while retailers operate the retail channel. This dual-channel structure is closer to reality. Moreover, the traditional $\mathrm{O} 2 \mathrm{O}$ channel management literature focuses on the environment where the online and offline operators (the manufacturer and retailer) do not create a partnership (e.g., [19-21]). Our work on $\mathrm{O} 2 \mathrm{O}$ is focused on an environment where the online and offline operators (the manufacturer and retailer) cooperate. Specifically, here, the direct channel operated by the manufacturer and the retail channel operated by the retailer collaborate to integrate to the $\mathrm{O} 2 \mathrm{O}$ omnichannel, and the two sides cooperate and drain each other. Second, we examine a new direction in the literature on MBG strategy. Previously, the literature on MBG has only considered providing single MBG service, not dual DMBG service, and did not discuss the combination of MBG with the increasingly popular $\mathrm{O} 2 \mathrm{O}$ strategy (e.g., $[1,7,8])$. We study the impact of $M B G$ and the more relaxed $D M B G$ and $\mathrm{O} 2 \mathrm{O}$ strategies in dual-channel Stackelberg competition when the manufacturer also has a direct channel. The significance of this study is that the manufacturer can provide the more relaxed DMBG service or cooperate with the retailer to establish an $\mathrm{O} 2 \mathrm{O}$ omnichannel to alleviate the pressure on the retailer to handle customer returns and ease the channel conflicts caused by opening the direct channel. Third, we show that the manufacturer's implementation of DMBG service does not always harm his own interest. In the initial stage of opening the direct channel, especially, DMBG can not only reduce the pressure on the retailer to handle customer returns and ease channel conflict but also increase the market share of the direct channel. Finally, we show that the $\mathrm{O} 2 \mathrm{O}$ strategy is more attractive to the retailer. If the retailer wishes to encourage the manufacturer to participate in the establishment of $\mathrm{O} 2 \mathrm{O}$ omnichannel, he should fully drain the online direct channel and improve the profitability of the online service.

The structure of this paper is as follows. Section 2 provides a literature review. Section 3 describes three models, including the model of no returns, the model of MBG, and the model of DMBG, and the selection and impact of return strategies and other situations are discussed. Section 4 studies the case of the $\mathrm{O} 2 \mathrm{O}$ strategy. Section 5 studies the selection of the $\mathrm{O} 2 \mathrm{O}$ strategy and return strategies. Section 6 concludes with a discussion of the management insights provided in this paper and recommendations for future research.

\section{Literature Review}

There are three strands of literature related to this paper: those on return strategy, pricing strategy in a dual-channel environment, and channel management. The first stream of related literature we address is that on return strategy. Return strategy is an important strategy for the manufacturer and retailer to maintain market competitiveness in general and in customer service in particular [3]. Manufacturers' return strategy for retailers is limited to excess inventory (e.g., [22-29]). As seen from the above literature, the manufacturer's return strategy is a guarantee for the retailer, which faces uncertain demand, thereby eliminating or reducing the retailer's sales risk and encouraging the retailer to maintain more inventories.

Retailers' return strategy is limited to consumer returns (see $[4,6,17,30,31])$. Retailers' return strategy for consumers can reduce consumers' perceived risk and encourage them to purchase, thereby enhancing their willingness to purchase and willingness to pay [8].

MBG return strategy is popular and often legally enforced. Most retail stores in the United States provide a comprehensive and relaxed return strategy; for example, the top ten apparel retailers in the United States provide return services [4]. The "Interim Measures for the Return without Reasons of Commodities Purchased Online within Seven Days" in the Consumer Rights and Interests Protection Law of China [32] stipulates that, in addition to special commodities, online shopping products allow consumers to return goods within seven days from the date of arrival. Manufacturers also provide retailers with relatively loose return services and do not allow retailers to return goods to reduce the pressure on retailers and standardize the treatment of returned goods. For example, both Hewlett-Packard and Bosch require retailers to return returned products to their respective manufacturers' return centers and refund the wholesale amount to the retailer in full [17]. Davis et al. 
[31] emphasize that manufacturers can use the corresponding return strategy to encourage retailers to provide a more generous return strategy. Focusing on channel interrelationships with respect to return strategies would be a worthwhile project for future research. Therefore, how should MBG return strategy be conducted, especially the manufacturer's return strategy? Is it a single MBG for customers only? Or should it be more relaxed, including not only customers but also retailers' DMBG? How do the manufacturer and the retailer choose their return strategy? How do the two return strategies of MBG and DMBG affect the pricing, market share and profit of the manufacturer and the retailer? How do the manufacturer and the retailer influence one another in providing return strategy? This series of issues is rarely addressed in previous studies, especially for DMBG. Therefore, research on the strategic interaction between MBG and DMBG for manufacturers and retailers is worthy of substantial consideration and research.

The second strand of literature concerns pricing strategy in a dual-channel environment. When studying dualchannel pricing, some works assume that the prices of the two channels should be the same (uniform) (e.g., $[20,33-36])$ and contend that a common channel price can alleviate channel conflict and maintain brand consistency. However, some studies argue that the prices of the two channels should be different (nonuniform) [19, 37, 38], and some works contend that online prices should be lower than offline prices because the operating cost of the online network channel is lower than the operating cost of the offline physical channel (e.g., [19, 37]). Other studies (e.g., [38]) argue that the online price should be higher than the offline price when most customers prefer the online channel. In our work, we consider both a situation based on the nonuniform pricing strategy and a situation based on the uniform pricing strategy. When the retailer and the manufacturer have not yet achieved channel cooperation, the nonuniform pricing strategy is implemented in the dual-channel system. We consider how the retailer and manufacturer decide their return strategy and how their pricing and return strategies affect competition between the two channels. When the retailer and the manufacturer achieve channel cooperation and build an $\mathrm{O} 2 \mathrm{O}$ omnichannel, the uniform pricing strategy (the same product at the same price) is implemented in the two channels. We also consider the conditions required to achieve channel cooperation between the retailer and the manufacturer and the impact of the $\mathrm{O} 2 \mathrm{O}$ strategy on the competition between the two channels.

Our work is also related to the management of online and offline channels. The traditional channel management literature focuses on the environment in which the online and offline channels do not achieve cooperation and different companies operate different channels (e.g., [19-21]). In contrast to this stream of work, our paper's work on $\mathrm{O} 2 \mathrm{O}$ focuses on the environment in which the online and offline channels achieve cooperation; that is, the retailer and the manufacturer realize channel cooperation and build an $\mathrm{O} 2 \mathrm{O}$ omnichannel. Similarly, an omnichannel environment and retailers managing both online and offline channels in an integrated manner have been considered in the literature
[39-41]. When considering such an omnichannel environment, most of the operational management literature focuses on how the new omnichannel cooperation process is implemented. For example, Gallino and Moreno [42] proposed an online and offline cooperation method for "buyonline, pick-up-in-store" (BOPS). Gao and Su [35] studied the implementation of BOPS and its impact on channel coordination from a theoretical perspective. Gallino et al. [43] investigated another widely used omnichannel implementation program, ship to store, and experience that has proven that the program can effectively improve the overall sales dispersion of retailers, with the lowest-selling products contributing the most. Our paper proposes a new online and offline cooperation method. Here, the retailer cooperates with the manufacturer to construct an $\mathrm{O} 2 \mathrm{O}$ omnichannel. The retailer's offline physical store (channel) provides display and experience services to customers, enhancing their sense of experience with and preference for brand products. It emphasizes the drainage from the offline channel to the online channel, whereby customers are introduced to more extensive product lines in the manufacturer's online direct channels to strengthen brand awareness and cultivate loyal customers.

Recent studies investigating returns, pricing, and $\mathrm{O} 2 \mathrm{O}$, including studies specifically related to the present work, are listed in Table 1.

\section{Modeling}

In this paper, we consider a single product sold in a dualchannel model with a retail channel and a direct channel, and the supply chain system contains only one manufacturer (M) and one retailer (R). The manufacturer not only wholesales products to the retailer at wholesale price $w$ but also opens a direct channel $(j=d)$ to sell directly to customers at direct price $p_{d}$. The retailer operates a retail channel $(j=r)$ at retail price $p_{r}$. In the fourth part of this paper, we note that, to attract customer traffic and increase the customer purchase rate, the retailer can cooperate with the manufacturer to build an $\mathrm{O} 2 \mathrm{O}$ omnichannel and implement the $\mathrm{O} 2 \mathrm{O}$ strategy, according to the advantages of its own channel. Under the $\mathrm{O} 2 \mathrm{O}$ strategy, the customer can choose to purchase products directly in the direct channel or to visit the physical retail store and experience the products before deciding whether to purchase in the retail channel.

3.1. The Traditional Model with No Returns. As a benchmark, we first discuss the traditional model. In the traditional model, the retailer and the manufacturer do not provide an MBG service to customers; that is, returns are not allowed. The retailer's revenue comes from retail channel sales revenue, and the manufacturer's revenue comes from direct channel sales revenue and wholesale revenue. The channel structure is shown in Figure 1.

Similar to many studies (such as [3]), we assume that a customer's willingness to pay for a product is $v$, and $v$ is subject to a uniform distribution based on $[0,1]$. After the customer purchases the product from channel $j$, if the 
TABle 1: Comparison among recent relevant studies.

\begin{tabular}{|c|c|c|c|c|c|c|}
\hline & $\begin{array}{l}\text { Channel } \\
\text { structure }\end{array}$ & MBG & DMBG & $\begin{array}{l}\text { Two pricing } \\
\text { strategies }\end{array}$ & $\mathrm{O} 2 \mathrm{O}$ & Major findings \\
\hline Davis et al. [31] & $\mathrm{M}$ & $\sqrt{ }$ & $x$ & $\times$ & $\times$ & MBG enhances profit (if net salvage value is positive) \\
\hline Chen and Chen [3] & $\mathrm{D}$ & $\sqrt{ }$ & $\times$ & $\times$ & $\times$ & $\begin{array}{l}\text { MBG mitigates price competition and may result in a Pareto } \\
\text { improvement in both retailers' profits }\end{array}$ \\
\hline McWilliams [4] & $\mathrm{D}$ & $\sqrt{ }$ & $\times$ & $\times$ & $\times$ & $\begin{array}{l}\text { MBG helps the low-quality retailer and harms the high-quality } \\
\text { retailer (if the net salvage value is positive) }\end{array}$ \\
\hline Chen and Chen [18] & $\mathrm{R}-\mathrm{D}$ & $\sqrt{ }$ & $\times$ & $\times$ & $\times$ & $\begin{array}{l}\text { MBG is the dominant choice for both channels (if the net salvage } \\
\text { value is positive) }\end{array}$ \\
\hline Xia et al. [44] & M-D & $\sqrt{ }$ & $\times$ & $\times$ & $\times$ & $\begin{array}{c}\text { The retailer's high service cost reduces the manufacturer's } \\
\text { incentive to add a direct channel in the presence of customer } \\
\text { returns }\end{array}$ \\
\hline Li et al. [45] & M-D & $\sqrt{ }$ & $\times$ & $\times$ & $x$ & $\begin{array}{c}\text { The manufacturer prefers to offer MBG in both channels if the } \\
\text { return rate is low }\end{array}$ \\
\hline Li et al. [1] & M-D & $\sqrt{ }$ & $\times$ & $\times$ & $\times$ & $\begin{array}{l}\text { MBG (if the net salvage value is positive) is the dominant choice } \\
\text { for retailer's channel, and the manufacturer may offer an MBG } \\
\text { even if the net salvage value is negative }\end{array}$ \\
\hline Heydari et al. [7] & M & $\sqrt{ }$ & $\sqrt{ }$ & $\times$ & $\times$ & DMBG can achieve Pareto-improving supply chain coordination \\
\hline $\begin{array}{l}\text { Gallino and Moreno } \\
{[42]}\end{array}$ & $\mathrm{R}-\mathrm{D}$ & $\times$ & $\times$ & $\times$ & $\sqrt{ }$ & $\begin{array}{c}\text { The } \mathrm{O} 2 \mathrm{O} \text { strategy of “BOPS” has a cross-selling effect and } \\
\text { channel-shifting effect }\end{array}$ \\
\hline Gao and $\mathrm{Su}[35]$ & $\mathrm{R}-\mathrm{D}$ & $\times$ & $\times$ & $\times$ & $\sqrt{ }$ & $\begin{array}{c}\text { The O2O strategy of "BOPS" enables retailers to reach new } \\
\text { customers, and its revenue can be shared across channels to } \\
\text { alleviate incentive conflicts }\end{array}$ \\
\hline Gallino et al. [43] & R-D & $\times$ & $x$ & $x$ & $\sqrt{ }$ & $\begin{array}{c}\text { The O2O strategy of "ship-to-store" can effectively improve the } \\
\text { overall sales dispersion of retailers, where the lowest-selling } \\
\text { products contribute the most }\end{array}$ \\
\hline Present study & M-D & $\sqrt{ }$ & $\sqrt{ }$ & $\sqrt{ }$ & $\sqrt{ }$ & $\begin{array}{l}\text { The handling loss with returns and the customer return cost for } \\
\text { each channel are critical factors that a retailer or manufacturer } \\
\text { should consider when choosing an MBG or a DMBG return } \\
\text { strategy. Moreover, the retailer should cooperate with the } \\
\text { manufacturer to establish an } \mathrm{O} 2 \mathrm{O} \text { omnichannel to make greater } \\
\text { use of the convenience and advantages of the retail channel }\end{array}$ \\
\hline
\end{tabular}

Decision is considered $(\sqrt{ })$ or not considered $(x)$. Channel structure: manufacturer's dual channel (M-D; manufacturer's dual channel in which the manufacturer operates a direct channel and the retailer operates a retail channel); retailer's dual channel (R-D; retailer's dual channel in which the retailer operates both direct channel and retail channel or a retailer operates a direct channel while another retailer operates a retail channel); duopoly (D; single channel of duopoly); Monopoly (M; single channel of monopoly). Pricing: uniform pricing and nonuniform pricing strategies are considered $(\sqrt{ })$ or not considered $(\times)$.

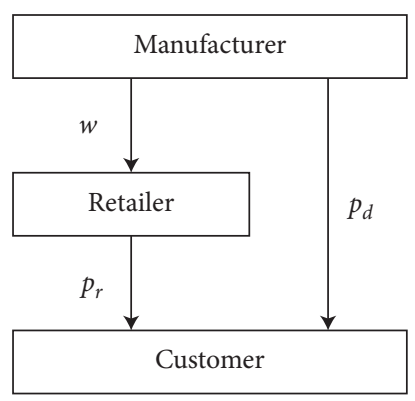

FIgURE 1: The traditional model with no returns.

product meets the customer's needs and the customer is satisfied with the product, he obtains utility $v-p_{j}$; however, if the customer is not satisfied with the product, he obtains utility $0-p_{j}$. Therefore, in the traditional model, where returns are not allowed, the expected utility of a retail channel customer is $U_{r}=a_{r}\left(v-p_{r}\right)+\left(1-a_{r}\right)$ $\left(0-p_{r}\right)=a_{r} v-p_{r}$; the expected utility of a direct channel customer is $U_{d}=a_{d} v-p_{d}$. Here, $\alpha_{j}$ is the customer satisfaction with channel $j$, which is closely related to the quality and service of shopping experience provided by channel $j$. Echoing the findings of Ofek et al. [33], we find that the retail channel is more accessible to customers, and customers can use "touch and feel" to determine whether they are satisfied with the product, so we assume that $\alpha_{r}>\alpha_{d}$. Customers make a choice by comparison of whether to buy in the retail channel, buy in the direct channel, or not buy; that is, their problem is $\max \left(U_{d}, U_{r}, 0\right)$.

Obviously, when $U_{r} \geq 0$ or $v \geq v_{r}^{N}=\left(p_{r} / \alpha_{r}\right)$, the customer is potentially willing to purchase the product via the retail channel; when $U_{d} \geq 0$ or $v \geq v_{d}^{N}=\left(p_{d} / \alpha_{d}\right)$, the customer is potentially willing to purchase the product via the direct channel; when $U_{r} \geq U_{d}$ or $v \geq v_{r d}^{N}=$ $\left(\left(p_{r}-p_{d}\right) /\left(\alpha_{r}-\alpha_{d}\right)\right)$, the customer prefers to buy the product via the retail channel but not the direct channel. Therefore, the demand for the direct channel is $D_{d}^{N}=v_{r d}^{N}-v_{d}^{N}$. The demand for the retail channel is $D_{r}^{N}=1-v_{r d}^{N}$.

In the case of a traditional dual-channel supply chain that does not allow returns, the retailer's profit is $\Pi_{r}^{N}=\max _{p_{r}}\left(p_{r}-w\right) D_{r}^{N}$; the profit of the manufacturer is $\Pi_{d}^{N}=\max _{p_{d}, w} w D_{r}^{N}+p_{d} D_{d}^{N}$, where $\Pi_{d 1}^{N}=w D_{r}^{N}$ is the 
wholesale profit for the manufacturer, and $\Pi_{d 2}^{N}=p_{d} D_{d}^{N}$ is the direct profit for the manufacturer. The manufacturer and the retailer engage in a Stackelberg game to maximize their respective interests. Because manufacturers are more competitive in the market, they are generally dominant and have complete information. The order of the game is as follows: the manufacturer (he) first sets his own direct price $p_{d}$ and wholesale price $w$ to maximize his own profits; then, the retailer (she) sets her retail price $p_{r}$ to maximize her revenue; finally, the customer decides whether and where to buy. Proposition 1 can be obtained through backward induction.

Proposition 1. In the case of a traditional dual-channel supply chain that does not allow returns, the optimal prices and wholesale price for the direct channel and the retail channel are

$$
\begin{aligned}
& p_{d}^{N}=\frac{\alpha_{d}}{2}, \\
& w^{N}=\frac{\alpha_{r}}{2}, \\
& p_{r}^{N}=\frac{3 \alpha_{r}-\alpha_{d}}{4} .
\end{aligned}
$$

The proof of Proposition 1 is shown in Appendix A.

Proposition 1 shows that the higher the customer satisfaction with the direct channel is, the higher the price in the direct channel is. The higher the customer satisfaction in the retail channel is, the higher the price in the retail channel is. Because the retail channel can approach and serve customers better, customer satisfaction is high $\left(\alpha_{r}>\alpha_{d}\right)$; therefore, as customer satisfaction increases, the change in the price of the retail channel becomes more significant. See Table 2 for details on the other parameters. According to Proposition 1, it is easy to obtain that the demand for the direct channel is $D_{d}^{N}=(1 / 4)$, the demand for the retail channel is $D_{r}^{N}=(1 / 4)$, and the profit of the manufacturer is $\Pi_{d}^{N}=\left(\left(\alpha_{d}+\alpha_{r}\right) / 8\right)$, where $\left(\alpha_{r} / 8\right)$ is the wholesale income $\Pi_{d 1}^{N},\left(\alpha_{d} / 8\right)$ is the direct income $\Pi_{d 2}^{N}$, and the retailer's profit is $\Pi_{r}^{N}=(1 / 16)\left(a_{r}-a_{d}\right)$.

3.2. The Model with a Money-Back Guarantee. We do not consider the case in which only one channel provides MBG service while the other channel does not. That is, in our paper, we consider MBG service being provided in either both channels or neither. This is because, in reality, we find that if only one channel provides MBG service, as long as it can process product returns-that is, the returned product has a net residual value greater than or equal to zero-then its competitiveness is better than another channel that does not. This finding has been verified in the literature $[1,18]$. Therefore, to fairly characterize channel competitiveness, we assume that either both channels provide MBG service or neither provides MBG service.

In the MBG model, we assume that the retailer and the manufacturer both provide MBG service to the customer, which allows the customer to return the product and receive
TABle 2: Sensitivity analysis of equilibrium demand, price, and profit under the no-returns strategy.

\begin{tabular}{cccccccccc}
\hline & $p_{r}^{N}$ & $p_{d}^{N}$ & $w^{N}$ & $D_{r}^{N}$ & $D_{d}^{N}$ & $\Pi_{r}^{N}$ & $\Pi_{d 1}^{N}$ & $\Pi_{d 2}^{N}$ & $\Pi_{d}^{N}$ \\
\hline$\alpha_{r}$ & $\uparrow$ & - & $\uparrow$ & - & - & $\uparrow$ & $\uparrow$ & - & $\uparrow$ \\
$\alpha_{d}$ & $\downarrow$ & $\uparrow$ & - & - & - & $\downarrow$ & - & $\uparrow$ & $\uparrow$ \\
\hline
\end{tabular}

a full refund, but the manufacturer does not accept the retailer's returns. Here, the customer's expected net utility in the retail channel is $U_{r}=a_{r}\left(v-p_{r}\right)-\left(1-a_{r}\right) t_{r}$. The customer's expected net utility in the direct channel is $U_{d}=a_{d}\left(v-p_{d}\right)-\left(1-a_{d}\right) t_{d}$, where $t_{j}$ is the average unit return cost of the returns to the channel $j$ when the customer is dissatisfied with the product, including the transportation cost of returning to the retail channel or the shipping cost of returning to the direct channel. Since the retail channel is more convenient for returns, we assume that $t_{r}<t_{d}$. The dual-channel structure is shown in Figure 2.

Similarly, when $U_{r} \geq 0$ or $v \geq v_{r}^{M}=\left(\left(1-\alpha_{r}\right) t_{r} / \alpha_{r}\right)+p_{r}$, the customer purchases the product via the retail channel; when $U_{d} \geq 0$ or $v \geq v_{d}^{M}=\left(\left(1-\alpha_{d}\right) t_{d} / \alpha_{d}\right)+p_{d}$, the customer purchases the product via the direct channel; when $U_{r} \geq U_{d}$ or $v \geq v_{r d}^{M}=\left(\left(\left(1-\alpha_{r}\right) t_{r}-\left(1-\alpha_{d}\right) t_{d}+\alpha_{r} p_{r}-\alpha_{d} p_{d}\right) /\left(\alpha_{r}-\alpha_{d}\right)\right)$, the customer prefers to buy the product via the retail channel but not the direct channel. Therefore, the demand for the direct channel is $D_{d}^{M}=v_{r d}^{M}-v_{d}^{M}$, and the demand for the retail channel is $D_{r}^{M}=1-v_{r d}^{M}$.

In the case of a dual-channel supply chain with MBG, the retailer's profit is $\Pi_{r}^{M}=\max _{p_{r}}\left[\alpha_{r} p_{r}-\left(1-\alpha_{r}\right) T_{r}\right]$ $D_{r}^{M}-w D_{r}^{M}$, and the profit of the manufacturer is $\Pi_{d}^{M}=\max _{p_{d}, w} w D_{r}^{M}+\left[\alpha_{d} p_{d}-\left(1-\alpha_{d}\right) T_{d}\right] D_{d}^{M}$, where $T_{j}$ is the cost (loss) of processing the returned product via channel $j$, such as the cost of repackaging and other handling of the returned product (i.e., the loss incurred by the handling of the returned product). Note that if the customer is not satisfied with the product, the return cost incurred by the customer is only the transportation cost of returning to the retail channel or the shipping cost of returning to the direct channel; the manufacturer with the direct channel not only has to bear the positive delivery cost but also the handing cost of the returned product, such as the cost of repacking the returned product; in addition, because the retailer has more sales experience and is more convenient, it is easier to handle the returned product at a smaller loss. Therefore, it is assumed that $t_{r}<t_{d}<T_{r}<T_{d}$. In addition, $\Pi_{d 1}^{M}=w D_{r}^{M}$ is the wholesale profit for the manufacturer, and $\Pi_{d 2}^{M}=\left[\alpha_{d} p_{d}-\left(1-\alpha_{d}\right) T_{d}\right] D_{d}^{M}$ is the direct profit for the manufacturer.

Next, we also use the Stackelberg game to obtain the equilibrium solution. Similarly, in the Stackelberg game, the manufacturer dominates and has complete information. The order of the game is as follows. The manufacturer first decides his direct price $p_{d}$ and wholesale price $w$. Then, the retailer decides her retail price $p_{r}$. Finally, the customer decides whether and where to buy. Proposition 2 is also obtained by backward induction.

Proposition 2. In the case of a dual-channel supply chain with an $M B G$, the direct channel and the retail channel 


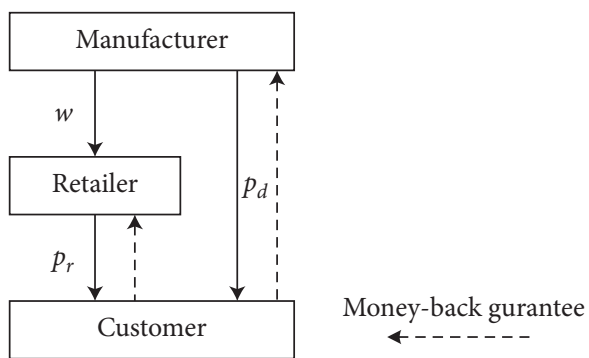

Figure 2: The model with money-back guarantee.

provide MBG service to customers, but the manufacturer does not accept the retailer's returns. The optimal prices and wholesale price for the direct channel and the retail channel are

$$
\begin{aligned}
& p_{d}^{M}=\frac{1}{2 \alpha_{d}}\left[\alpha_{d}+\left(1-\alpha_{d}\right)\left(T_{d}-t_{d}\right)\right], \\
& w^{M}=\frac{1}{2}\left[\alpha_{r}-\left(1-\alpha_{r}\right)\left(T_{r}+t_{r}\right)\right], \\
& p_{r}^{M}=\frac{1}{4 \alpha_{r}}\left[3 \alpha_{r}-\alpha_{d}+\left(1-\alpha_{r}\right)\left(T_{r}-3 t_{r}\right)+\left(1-\alpha_{d}\right)\left(T_{d}+t_{d}\right)\right] .
\end{aligned}
$$

The proof of Proposition 2 is shown in Appendix A.

According to Proposition 2 and Table 3, when direct sales channels and retail channels provide MBG service to customers, that is, customers are allowed to return, but the manufacturer does not accept the retailer's returns, the optimal decision of the manufacturer and the retailer will be affected by their channel customer satisfaction, the loss from handling returns, the customer return cost, among other factors. We obtain the following findings.

(i) As the loss from handling customer returns in the retail channel $T_{r}$ increases, the retail price in the retail channel will increase, and the manufacturer's optimal wholesale price will decline accordingly. This means that when customer returns entail a large loss for the retailer, the retailer will implement a high-price strategy to prevent some customers who might return the product from buying the product in the retail channel, thereby avoiding the risk of return loss; however, to curb the high retail price in the retail channel, the manufacturer will reduce wholesale prices to mitigate the negative impact of high prices on product demand.

(ii) As the loss to the manufacturer from handling customer returns in the direct channel $T_{d}$ increases, the direct price in the direct channel will increase, but the wholesale price will not change. This means that when customer returns entail a substantial loss in the manufacturer's direct channel, the manufacturer will implement a high-price strategy to prevent some customers who might return the product from purchasing in the direct channel and
TABLE 3: Sensitivity analysis of equilibrium demand, price, and profit under MBG strategy.

\begin{tabular}{cccccccccc}
\hline & $p_{r}^{M}$ & $p_{d}^{M}$ & $w^{M}$ & $D_{r}^{M}$ & $D_{d}^{M}$ & $\Pi_{r}^{M}$ & $\Pi_{d 1}^{M}$ & $\Pi_{d 2}^{M}$ & $\Pi_{d}^{M}$ \\
\hline$\alpha_{r}$ & $\uparrow$ & - & $\uparrow$ & $\downarrow$ & $\uparrow$ & $\uparrow$ & $\uparrow$ & $\uparrow$ & $\uparrow$ \\
$\alpha_{d}$ & $\downarrow$ & $\downarrow$ (micro) & - & $\uparrow$ (micro) & $\uparrow$ & $\downarrow$ & $\uparrow$ (micro) & $\uparrow$ & $\uparrow$ \\
$T_{r}$ & $\uparrow$ & - & $\downarrow$ & $\downarrow$ & $\uparrow$ & $\downarrow$ & $\downarrow$ & $\uparrow$ & $\downarrow$ \\
$T_{d}$ & $\uparrow$ & $\uparrow$ & - & $\uparrow$ & $\downarrow$ & $\uparrow$ & $\uparrow$ & $\downarrow$ & $\downarrow$ \\
$t_{r}$ & $\downarrow$ & - & $\downarrow$ & $\downarrow$ & $\uparrow$ & $\downarrow$ & $\downarrow$ & $\uparrow$ & $\downarrow$ \\
$t_{d}$ & $\uparrow$ & $\downarrow$ & - & $\uparrow$ & $\downarrow$ & $\uparrow$ & $\uparrow$ & $\downarrow$ & $\downarrow$ \\
\hline
\end{tabular}

avoid the risk of return loss. However, to ensure product demand, the manufacturer will not change the wholesale price, so some customers who were originally purchasing in the direct channel will turn to the retail channel to buy, and demand in the retail channel will rise.

(iii) As the retail channel customer return cost $t_{r}$ increases, to restrain the sharp decrease in demand in the retail channel, the retailer will reduce the retail price, and the manufacturer's optimal wholesale price will also be appropriately reduced to compensate for the loss of retailers. Moreover, some customers who formerly purchased in the retail channel will shift to purchasing in the direct channel, so the demand for the direct channel will increase.

(iv) As the return cost for customers in the direct channel $t_{d}$ increases, the manufacturer will reduce the direct price to curb the sharp decrease in demand in the direct channel. Moreover, some customers in the direct channel will shift to the retail channel for purchasing, and the demand in the retail channel will rise.

In addition, we found a more interesting phenomenon in Table 3. (i) As customer satisfaction in the retail channel increases, demand in the retail channel decreases. This occurs because when customer satisfaction in the retail channel is high, the manufacturer will increase the wholesale price, which will increase the retail price. The negative impact of the rising retail price is greater than the positive impact of the rising customer satisfaction, which reduces the demand in the retail channel. However, as customer satisfaction with the retail channel increases, the loss from handling customer returns is substantially reduced, and even if demand is reduced, the retail channel profit nevertheless increases. (ii) When customer satisfaction in the direct channel increases, the demand for both channels increases, but the increase in demand in the direct channel is greater than that in the retail channel, which also shows that channel customer satisfaction has a greater impact on channel demand than do other channels.

Finally, according to Proposition 2, the demands in the direct channel and the retail channel and the profits of the manufacturer and the retailer in this case of MBG can be obtained. The details are shown in Table 4.

Proposition 3. The impact of the MBG strategy on the retailer and manufacturer's optimal pricing decisions is as follows: $p_{r}^{M}>p_{r}^{N} ; p_{d}^{M}>p_{d}^{N} ; w^{M}<w^{N}$. 
TABLE 4: Coefficients of demands and profits with the MBG strategy.

\begin{tabular}{lc}
\hline Coefficient & Value \\
\hline$D_{d}^{M}$ & $\left(1 / 4 \alpha_{d}\left(\alpha_{r}-\alpha_{d}\right)\right)\left[\left(\alpha_{r}-\alpha_{d}\right) \alpha_{d}-\left(1-\alpha_{d}\right)\left(2 \alpha_{r}-\alpha_{d}\right)\left(T_{d}+t_{d}\right)+\left(1-\alpha_{r}\right) \alpha_{d}\left(T_{r}+t_{r}\right)\right]$ \\
$D_{r}^{M}$ & $\left(1 / 4\left(\alpha_{r}-\alpha_{d}\right)\right)\left[\left(\alpha_{r}-\alpha_{d}\right)-\left(1-\alpha_{r}\right)\left(T_{r}+t_{r}\right)+\left(1-\alpha_{d}\right)\left(T_{d}+t_{d}\right)\right]$ \\
$\Pi_{d 1}^{M}$ & $\left(1 / 8\left(\alpha_{r}-\alpha_{d}\right)\right)\left\{\left[\alpha_{r}-\left(1-\alpha_{r}\right)\left(T_{r}+t_{r}\right)\right] \cdot\left[\left(\alpha_{r}-\alpha_{d}\right)-\left(1-\alpha_{r}\right)\left(T_{r}+t_{r}\right)+\left(1-\alpha_{d}\right)\left(T_{d}+t_{d}\right)\right]\right\}$ \\
$\Pi_{d 2}^{M}$ & $\left(1 / 8 \alpha_{d}\left(\alpha_{r}-\alpha_{d}\right)\right)\left\{\left[\alpha_{d}-\left(1-\alpha_{d}\right)\left(T_{d}+t_{d}\right)\right] \cdot\left[\alpha_{d}\left(\alpha_{r}-\alpha_{d}\right)-2 \alpha_{r}\left(1-\alpha_{d}\right)\left(T_{d}+t_{d}\right)+\alpha_{d}\left(1-\alpha_{r}\right)\left(T_{r}+t_{r}\right)+\alpha_{d}\left(1-\alpha_{d}\right)\left(T_{d}+t_{d}\right)\right]\right\}$ \\
$\Pi_{d}^{M}$ & $\Pi_{d 1}^{M}+\Pi_{d 2}^{M}$ \\
$\Pi_{r}^{M}$ & $\left(1 / 16\left(\alpha_{r}-\alpha_{d}\right)\right)\left[\left(1-\alpha_{r}\right)\left(T_{r}+t_{r}\right)-\left(1-\alpha_{d}\right)\left(T_{d}+t_{d}\right)-\left(\alpha_{r}-\alpha_{d}\right)\right]^{2}$ \\
\hline
\end{tabular}

The proof of Proposition 3 is shown in Appendix A.

According to Proposition 3, the optimal pricing decisions of the retailer and the manufacturer are affected by the MBG. The MBG strategy will result in a "downward distortion" of the optimal wholesale price $\left(w^{M}<w^{N}\right)$. However, the retailer does not necessarily reduce the retail price in the retail channel, and the manufacturer does not necessarily reduce the direct price in the direct channel. The price in each channel depends primarily on the size of the loss from handling customer returns. As mentioned above, the retailer and manufacturer raise sales prices as their losses from handling customer returns increase. However, the MBG strategy can alleviate the uncertainty in customer purchases to a certain extent, and customers need to pay a premium for this service. To curb the retailer's high-price strategy, the manufacturer will reduce the wholesale price to alleviate the negative impact of the high-price strategy on product demand.

The customer return behavior will cause losses for the retailer and the manufacturer due to losses from returns in the supply chain. Therefore, when the retailer/manufacturer's loss from handling returns is large, the retailer/ manufacturer will raise the sales price, which can prevent some customers with a lower valuation from purchasing to avoid more return losses.

Proposition 4. The MBG strategy can effectively increase the demand and profit in the retail channel as follows: when $T_{d}+t_{d}>T_{r}+t_{r}$, then $D_{r}^{M}>D_{r}^{N}, \prod_{r}^{M}>\prod_{r}^{N}$.

The proof of Proposition 4 is shown in Appendix A.

Proposition 5. The MBG strategy can reduce the demand and profit in the direct channel but can increase the wholesale profit of the manufacturer as follows.

(i) When $T_{d}+t_{d}>T_{r}+t_{r}$, then $D_{d}^{M}<D_{d}^{N}, \prod_{d 2}^{M}>\prod_{d 2}^{N}$.

(ii) When $T_{d}+t_{d}>T_{r}+t_{r}$ and $\alpha_{r}>\left(1-\alpha_{r}\right)\left(T_{r}+t_{r}\right)$, then $\prod_{d 1}^{M}>\prod_{d 1}^{N}$.

The proof of Proposition 5 is shown in Appendix A.

Propositions 3 and 5 show that the MBG strategy can eliminate the purchasing uncertainty of online customers in the direct channel and reduce the risk that customers will not be satisfied with the products; however, due to the loss from handling customer returns, the manufacturer will increase the sales price in the direct channel, thus reducing the demand and profit in the direct channel. According to Propositions 3 and 4, the retail price in the retail channel also increases due to handling returns after providing an MBG strategy, but the demand and profit in the retail channel are not affected; in fact, the MBG strategy can effectively enhance the demand and profit in the retail channel. This is because the retail channel facilitates contact with and service of customers relative to the direct channel, so both the loss from handling returns and the customer return cost are smaller than those in the direct channel, which makes it more likely for customers to accept the retail channel and increase both demand and profit.

Notably, the previous conclusions are based on $T_{d}>T_{r}$ and $t_{d}>t_{r}$. Thus, if the manufacturer can reduce the loss incurred by handling customer returns in the direct channel, the direct channel is convenient enough, and the customer return cost is low enough to obtain $T_{d}<T_{r}$ and $t_{d}<t_{r}$; the MBG strategy can increase demand in the direct channel, thereby increasing the profitability of the manufacturer's direct channel.

3.3. The Model with a Dual Money-Back Guarantee. Similar to the case in Section 3.2, in this section, we assume that the retailer provides an MBG to customers; here the manufacturer also provides DMBG service. This means that the manufacturer not only provides MBG service to the direct channel customers but also provides MBG service to the retailer, accepting returns from retail channel customers and providing a full refund of the wholesale price to the retailer. For example, both Hewlett-Packard and Bosch allow retailers to return the returned products to their respective manufacturers' return centers for processing and provide a full refund of the wholesale price to retailers [17]. Because the manufacturer accepts customer returns from the retail channel, the retailer does not need to repack or otherwise handle the returned product or resell the returned product at a discount and only needs to return the customer returned product to the manufacturer, which is equivalent to the retailer's loss from handling customer returns being largely transferred to the manufacturer. Therefore, in the DMBG model, for the convenience of calculation and without affecting the results, we assume that the retailer's loss from handling customer returns is zero $\left(T_{r}=0\right)$; however, the manufacturer has to bear the loss from handling customer returns from the retail channel. We assume that the manufacturer's loss from handling customer returns in the retail channel returns is the same as that in the direct channel, both of which are $T_{d}$, and the manufacturer also provides the MBG service with a full refund to the retailer, but notably, the manufacturer gives the retailer a refund amount of $w$.

Because Section 3.3 is similar to 3.2 , customers are allowed to return products with which they are dissatisfied and obtain a full refund, so the customer's expected net 
utility and demand function are unchanged. However, the profit functions of the retailer and the manufacturer change because the manufacturer is accepting customer returns from the retail channel. The retailer's profit is $\Pi_{r}^{D M}=\max _{p_{r}} \alpha_{r}\left(p_{r}-w\right) D_{r}^{D M}$. The manufacturer's profit is $\Pi_{d}^{D M}=\max _{p_{d}, w}\left[\alpha_{r} w-\left(1-\alpha_{r}\right) T_{d}\right] D_{r}^{D M}+\left[\alpha_{d} p_{d}-\left(1-\alpha_{d}\right)\right.$ $\left.T_{d}\right] D_{d}^{D M}$.

The dual-channel structure of the DMBG model is shown in Figure 3.

We also use the Stackelberg game to obtain an equilibrium solution. Similarly, in this Stackelberg game, the manufacturer dominates and has complete information. The order of the game is as follows. The manufacturer first decides his direct price $p_{d}$ and wholesale price $w$. Then, the retailer decides her retail price $p_{r}$. Finally, the customer decides whether and where to buy. Proposition 6 can be obtained by backward induction.

Proposition 6. In the case of a dual-channel supply chain with a $D M B G$, the optimal pricing and wholesale price for the direct and retail channels are

$$
\begin{aligned}
& p_{d}^{D M}=\frac{1}{2 \alpha_{d}}\left[\alpha_{d}+\left(1-\alpha_{d}\right)\left(T_{d}-t_{d}\right)\right], \\
& w^{D M}=\frac{1}{2 \alpha_{r}}\left[\alpha_{r}+\left(1-\alpha_{r}\right)\left(T_{d}-t_{r}\right)\right], \\
& p_{r}^{D M}=\frac{1}{4 \alpha_{r}}\left[3 \alpha_{r}-\alpha_{d}+\left(1-\alpha_{r}\right)\left(T_{d}-3 t_{r}\right)+\left(1-\alpha_{d}\right)\left(T_{d}+t_{d}\right)\right] .
\end{aligned}
$$

The proof of Proposition 6 is shown in Appendix A.

According to Proposition 6, under the DMBG strategy, the optimal decisions of the manufacturer and retailer are affected by loss from handling customer returns and the consumer return cost. Moreover, since the manufacturer accepts the customer returns from the retail channel, the retailer's loss from handling the returns is transferred to the manufacturer; that is, $T_{r}=0$. Table 5 indicates that the parameter changes under the DMBG strategy are basically the same as those under the MBG strategy. One important difference is that when the manufacturer faces substantial costs from handling customer returns, the manufacturer would raise the wholesale price to compensate for the loss from handling returns caused by providing DMBG to the retailer.

Due to the high wholesale price, the retailer also increases the retail price. However, note that the direct price under the DMBG strategy is the same as the direct price under the MBG strategy, which indicates that the price in a given channel is closely related to the return strategy in that channel but has nothing to do with other return strategies in other channels.

Similarly, according to Proposition 6, the demands in the direct and retail channels in the case of DMBG are $D_{d}^{D M}$ and $D_{r}^{D M}$, and the profits of the manufacturer and retailer are $\Pi_{d}^{D M}$ and $\Pi_{r}^{D M}$. The details are shown in Table 6.

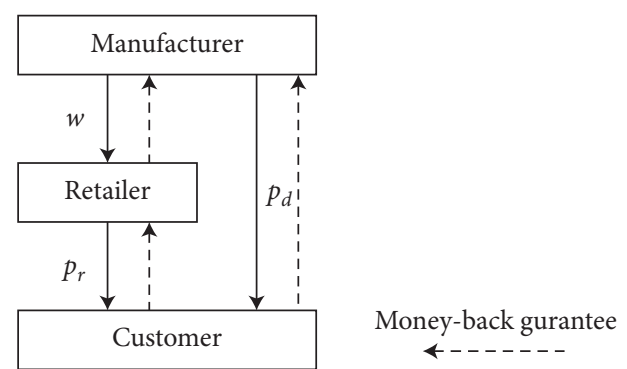

FIGURE 3: The model with a dual money-back guarantee.

3.4. Return Strategy Selection and the Impact of a DualChannel Environment. Return services are increasingly valued by manufacturers, retailers, and customers. In many countries, MBG services are legally binding, and return strategy has clearly become an important strategy for manufacturers and retailers to exercise. Thus, it is worthwhile and interesting to investigate what kind of return strategy the manufacturer and retailer should choose. In this section, we discuss the impact of the MBG and DMBG strategies on the competition between the manufacturer and retailer in a dual-channel supply chain.

\subsubsection{The Impact of the Return Strategy on Pricing}

Proposition 7. The impact of the $M B G$ and $D M B G$ strategies on the retailer and manufacturer's optimal pricing decisions is compared as follows.

(i) When $T_{d}>T_{r}$, then $p_{r}^{D M}>p_{r}^{M}$.

(ii) $p_{d}^{D M}=p_{d}^{M}, w^{D M}>w^{M}$.

The proof of Proposition 7 is shown in Appendix A.

Under the DMBG strategy, the manufacturer will increase the wholesale price $\left(w^{D M}>w^{M}\right)$ to compensate for loss from handling the retailer's returns, which means that the DMBG strategy can, to some extent, alleviate the pressure on the retailer to process returns, and the retailer must pay a premium for DMBG service. Due to the high wholesale price, the retailer will also increase the retail price $\left(p_{r}^{D M}>p_{r}^{M}\right)$, which also means that customers pay a premium for the DMBG service that the retailer actually enjoys. Interestingly, we find that the direct price set by the manufacturer under the DMBG strategy is the same as that under the MBG strategy $\left(p_{d}^{D M}=p_{d}^{M}\right)$. This is because the direct price is related to the return strategy in the direct channel and has nothing to do with the return strategy in the retail channel.

From a supply chain perspective, since the return behavior of customers and retailers will bring losses for the manufacturer, when the return loss of the manufacturer is large, the manufacturer will increase the wholesale price under the DMBG strategy. The retailer will increase the retail price to prevent some customers in the retail channel who have lower valuations from purchasing products to avoid more return losses.

To directly observe the impact of the MBG and DMBG strategies on the sales price in the retail channel and direct channel, we set the parameters $T_{d}=0.04, T_{r}=0.02, t_{d}=0.02$, 
TABLE 5: Sensitivity analysis of equilibrium demand, price, and profit under the DMBG strategy.

\begin{tabular}{lcccccccc}
\hline & $p_{r}^{D M}$ & $p_{d}^{D M}$ & $w^{D M}$ & $D_{r}^{D M}$ & $D_{d}^{D M}$ & $\Pi_{r}^{D M}$ & $\Pi_{d 1}^{D M}$ & $\Pi_{d 2}^{D M}$ \\
\hline$\alpha_{r}$ & $\uparrow$ & - & $\downarrow$ & $\downarrow$ & $\uparrow$ & $\uparrow$ & $\Pi_{d}^{D M}$ \\
$\alpha_{d}$ & $\downarrow$ & $\downarrow$ (micro) & - & $\uparrow$ (micro) & $\uparrow$ & $\downarrow$ & $\uparrow$ & $\uparrow$ \\
$T_{d}$ & $\uparrow$ & $\uparrow$ & $\uparrow$ & $\uparrow$ & $\downarrow$ & $\uparrow$ & $\uparrow$ \\
$t_{r}$ & $\downarrow$ & - & $\downarrow$ & $\downarrow$ & $\uparrow$ & $\uparrow$ & $\uparrow$ & $\uparrow$ \\
$t_{d}$ & $\uparrow$ & $\downarrow$ & - & $\uparrow$ & $\downarrow$ & $\uparrow$ & $\downarrow$ & $\downarrow$ \\
\hline
\end{tabular}

TABle 6: Coefficients of demands and profits with the DMBG strategy.

\begin{tabular}{lc}
\hline Coefficient & Value \\
\hline$D_{d}^{D M}$ & $\left(1 / 4 \alpha_{d}\left(\alpha_{r}-\alpha_{d}\right)\right)\left[\left(\alpha_{r}-\alpha_{d}\right)\left(\alpha_{d}-\left(2-\alpha_{d}\right) T_{d}\right)-\left(1-\alpha_{d}\right)\left(2 \alpha_{r}-\alpha_{d}\right) t_{d}+\alpha_{d}\left(1-\alpha_{r}\right) t_{r}\right]$ \\
$D_{r}^{D M}$ & $\left(1 / 4\left(\alpha_{r}-\alpha_{d}\right)\right)\left[\left(\alpha_{r}-\alpha_{d}\right)+\left(\alpha_{r}-\alpha_{d}\right) T_{d}+\left(1-\alpha_{d}\right) t_{d}-\left(1-\alpha_{r}\right) t_{r}\right]$ \\
$\Pi_{d 1}^{D M}$ & $\left(1 / 8\left(\alpha_{r}-\alpha_{d}\right)\right)\left[\alpha_{r}-\left(1-\alpha_{r}\right)\left(T_{d}-t_{r}\right)\right]\left[\left(\alpha_{r}-\alpha_{d}\right)-\left(\alpha_{r}-\alpha_{d}\right) T_{d}+\left(1-\alpha_{d}\right) t_{d}-\left(1-\alpha_{r}\right) t_{r}\right]$ \\
$\Pi_{d 2}^{D M}$ & $\left(1 / 8 \alpha_{d}\left(\alpha_{r}-\alpha_{d}\right)\right)\left[\alpha_{d}-\left(1-\alpha_{d}\right)\left(T_{d}+t_{d}\right)\right]\left[\left(\alpha_{r}-\alpha_{d}\right)\left(\left(2-\alpha_{d}\right) T_{d}-\alpha_{d}\right)+\left(1-\alpha_{d}\right)\left(2 \alpha_{r}-\alpha_{d}\right) t_{d}-\left(1-\alpha_{r}\right) \alpha_{d} t_{r}\right]$ \\
$\Pi_{d}^{D M}$ & $\Pi_{d 1}^{D M}+\Pi_{d 2}^{D M}$ \\
$\Pi_{r}^{D M}$ & $\left(1 / 16\left(\alpha_{r}-\alpha_{d}\right)\right)\left[\left(\alpha_{r}-\alpha_{d}\right)+\left(\alpha_{r}-\alpha_{d}\right) T_{d}+\left(1-\alpha_{d}\right) t_{d}-\left(1-\alpha_{r}\right) t_{r}\right]^{2}$ \\
\hline
\end{tabular}

and $t_{r}=0.01$. Note that, in this paper, there is no product differentiation in the dual-channel supply chain, so customer satisfaction levels in the two channels often jointly increase or decrease. According to the National Retail Federation [10] and Ratcliff [11], satisfaction with e-commerce channels is only $0.65-0.87$ times the satisfaction with traditional retail channels. Therefore, we take the parameters $\alpha_{d}=0.75 \alpha_{r}$ and $\alpha_{r}=0.4: 0.05: 1$ to draw the curves representing the relationship between the retail and direct price and wholesale price with customer satisfaction, as shown in Figures 4 and 5. We find the following. (i) In the absence of an MBG, the sales price in each channel and the wholesale price will always increase in customer satisfaction, thereby generating more profits. (ii) In the case of the MBG strategy, due to the return service provided, customers have to pay a premium for the MBG, so the sales prices in both the retail channel and the direct channel are higher than in the absence of a return service guarantee. (iii) In the case of the DMBG strategy, since the retailer also enjoys the $\mathrm{MBG}$ service, although the pressure on customer returns is reduced, a certain premium for the service is also required $\left(w^{D M}>w^{M}\right)$, so customers also have to pay the same premium $\left(p_{r}^{D M}>p_{r}^{M}\right)$. Under the DMBG strategy, the direct price is the same as in the case of the MBG strategy $\left(p_{d}^{D M}=p_{d}^{M}\right)$. This also indirectly illustrates the fairness of the manufacturer. It does not transfer the loss suffered in the retail channel to the customers of the direct channel, which is more beneficial for generating consumer trust.

\subsubsection{The Impact of the Return Strategy on Market Share and Profit}

Proposition 8. The impact of the $M B G$ and the $D M B G$ strategies on the market share and profitability of the retail and direct channels is as follows.

(i) When $T_{d}>T_{r}$, then $D_{r}^{D M}<D_{r}^{M}, D_{d}^{D M}<D_{d}^{M}$.

(ii) When $T_{d}>T_{r}$ and $t_{d}>t_{r}$, then $\Pi_{r}^{D M}<\Pi_{r}^{M}$.

(iii) When $T_{d}>T_{r}$ and $\Delta_{r}>0$, then $\Pi_{d 1}^{D M}<\Pi_{d 1}^{M}$.

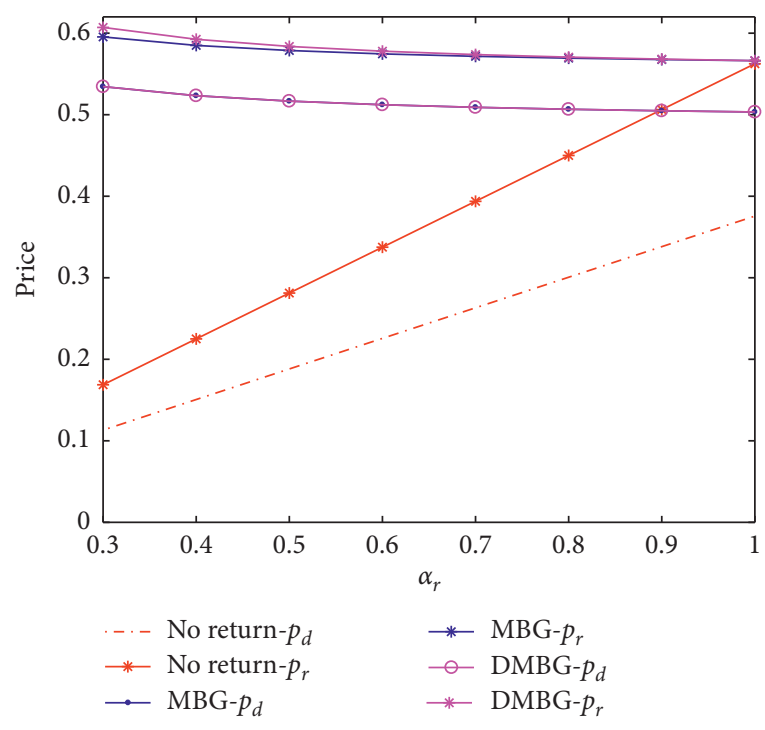

Figure 4: Price changes with $\alpha_{r}$.

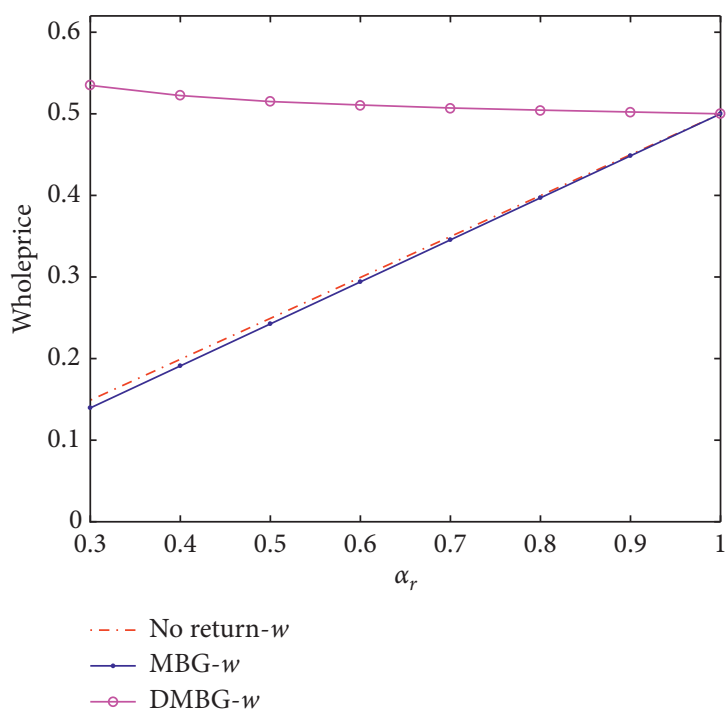

Figure 5: Wholesale price changes with $\alpha_{r}$. 
(iv) When $T_{d}>T_{r}$ and $\Delta_{d}>0$, then $\Pi_{d 1}^{D M}<\Pi_{d 1}^{M}$.

The proof of Proposition 8 in shown in Appendix A.

For the convenience of expression, we define $\Delta_{j}=\alpha_{j}-$ $\left(1-\alpha_{j}\right)\left(T_{j}+t_{j}\right)$ as the net residual value of satisfaction for selling products and providing return services through channel $j$, which also represents the supply chain's efficiency in selling the product and providing return services through channel $j$. Propositions 7 and 8 show that when the retailer's loss from handling the returns from the retail channel and the cost of a customer's return are both small, the retailer would not be willing to choose a DMBG strategy and instead prefers an MBG strategy. Obviously, when the manufacturer provides a return service for the retailer, the retailer needs to pay a premium for that service, thereby reducing the market share of the retail channel and decreasing profits. Moreover, due to the increase in the retail price, some customers with a purchase intention but a low willingness to pay turn to the direct channel, so the market share of the direct channel increases.

Note that, with $T_{d}>T_{r}$ alone, it is not possible to determine which return strategy the manufacturer implements. Only when the manufacturer can also efficiently handle customer returns through the retail channel $\left(\Delta_{r}>0\right)$ and the wholesale profit contributes to the manufacturer's overall profit will the manufacturer select the $\mathrm{MBG}$ return strategy. When the manufacturer efficiently handles customer returns through the direct channel $\left(\Delta_{d}>0\right)$ and the direct channel operation is the primary strategy of the manufacturer, the manufacturer will select the DMBG return strategy.

To directly observe the impact of the MBG and DMBG strategies on the market shares of the retail channel and direct channel, we set the same parameters to map the market shares of the retail channel and direct channel with respect to customer satisfaction. Figure 6 reveals the following. (i) When customer satisfaction is low, regardless of whether the MBG or DMBG strategy is in place, the return strategy can effectively increase the market share of the retail channel. When customer satisfaction is high, the incentive effect of the return strategy is gradually reduced, the demand in the retail channel thus declines, and its market share is reduced. (ii) However, the direct channel experiences the opposite effects from the retail channel. When customer satisfaction is low, return strategies reduce the market share of the direct channel. This is because the customer return cost in the direct channel is higher than that in the retail channel, so most customers choose to buy in the retail channel, and the market share of the direct channel is small. When customer satisfaction is high, some customers choose to turn to the direct channel for purchasing, the demand for the direct channel increases, and its market share increases. The market share of the direct sales channel under the DMBG strategy is larger than that under the MBG strategy. This is because the direct price under the DMBG strategy is the same as that under the MBG strategy, and the retail price under the DMBG strategy is higher than that under the MBG strategy, so that some customers with purchase intention but low perceived willingness to pay turn to the direct channel for purchasing, which also makes the

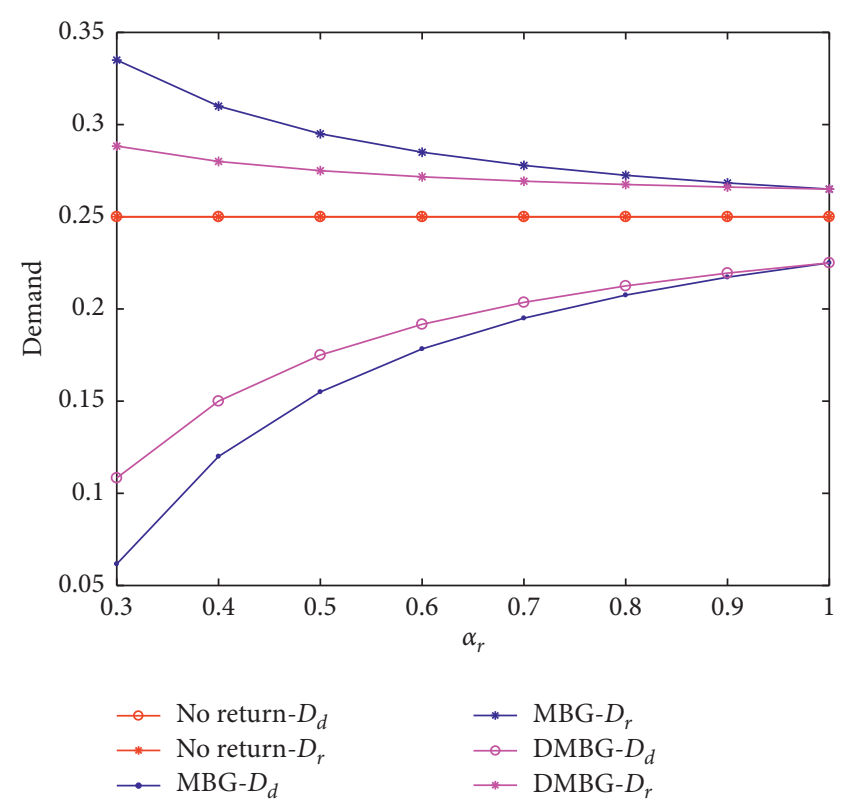

FIgURE 6: Market share changes with $\alpha_{r}$.

market share of the direct marketing channel under the DMBG strategy higher than that under MBG strategy. We analyze profits in the next section.

3.5. Other Situations. Proposition 8 is the conclusion obtained when the manufacturer's loss from handling returns and the customer return cost through the direct channel are both large $\left(T_{d}>T_{r}, t_{d}>t_{r}\right)$. However, under other circumstances, how will the impact of the DMBG and MBG strategies on the profitability of the retailer and manufacturer change? To visually clarify the impact of the DMBG and $\mathrm{MBG}$ strategies on the profitability of the retail and direct channels under other circumstances, we plot curves depicting conditions under these other circumstances are plotted. We set roughly the same parameter values as above, taking the parameters $\alpha_{d}=0.75 \alpha_{r}, \alpha_{r}=0.3: 0.05: 1$, and $T_{d}$ taking $(0.04,0.02,0.02), T_{r}$ taking $(0.02,0.04,0.02), t_{r}$ taking $(0.01,0.02,0.02)$, and $t_{d}$ taking $(0.02,0.01,0.02)$, to ensure the net residual value of satisfaction $\Delta_{j} \geq 0$. Moreover, denote $\Delta \Pi_{r}^{D M}=\Pi_{r}^{D M}-\Pi_{r}^{M}, \quad \Delta \Pi_{d 2}^{D M}=\Pi_{d 2}^{D M}-\Pi_{d 2}^{M}$, $\Delta \Pi_{d}^{D M}=\Pi_{d}^{D M}-\Pi_{d}^{M}$ as the DMBG strategy's impact on "the retail channel profit," "the direct channel profit," and "the manufacturer profit" relative to the MBG strategy. Figures 7-9 show the influence of $\Delta \Pi_{r}^{D M}, \Delta \Pi_{d 2}^{D M}$, and $\Delta \Pi_{d}^{D M}$ under three circumstances of " $T_{d}>T_{r}, t_{d}>t_{r}$," " $T_{d}<T_{r}$, $t_{d}<t_{r}$ " and " $T_{d}=T_{r}, t_{d}=t_{r}$ "

As Figures 7-9 and Proposition 8 show the following.

(i) When the retailer's loss from handling returns and the customer return cost are both low $\left(T_{d}>T_{r}, t_{d}>t_{r}\right)$, the MBG strategy is more favorable for the retailer. However, the DMBG strategy benefits the manufacturer's direct channel, but because the wholesale profit in practice is often greater than the direct profit (the wholesale profit dominates), the MBG strategy is more beneficial to 


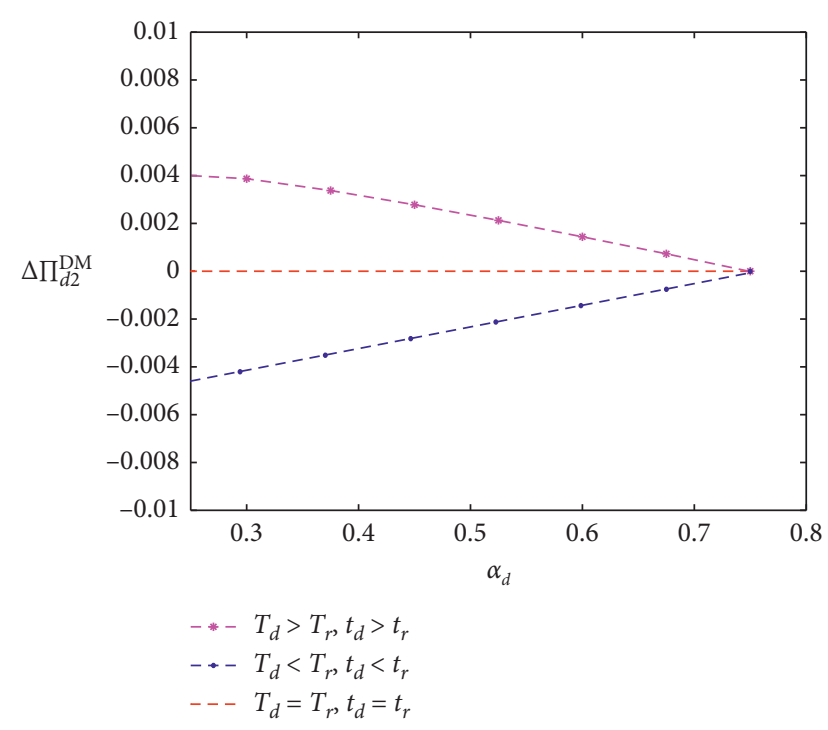

Figure 7: $\Delta \Pi_{d 2}^{D M}$ changes with $\alpha_{r}$.

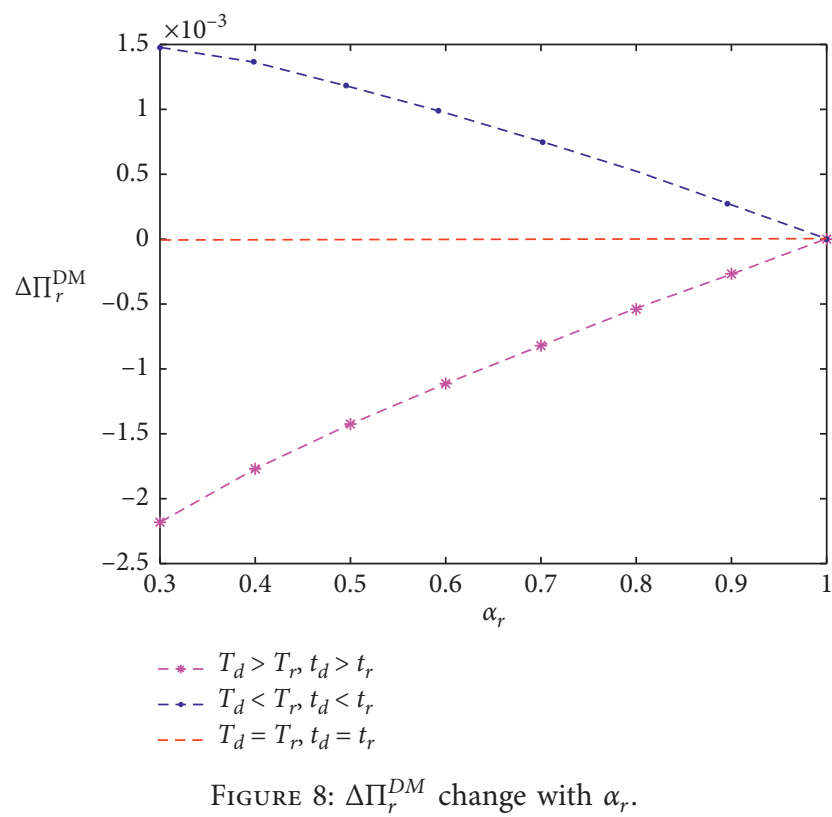

the manufacturer's overall profit. Furthermore, if the manufacturer wants to support the direct channel and cultivate customers in the direct channel, the manufacturer should consider implementing the DMBG strategy, which can not only rapidly increase the market share and profit of the direct channel but also compensate the retailer providing MBG service for return losses to ease channel conflicts caused by opening direct channel.

(ii) When the manufacturer's loss from handling channel returns and the customer return cost are both low $\left(T_{d}<T_{r}, t_{d}<t_{r}\right)$, the DMBG strategy is more advantageous for the retailer. However, the MBG strategy benefits the direct channel, but because the wholesale profit is often greater than the

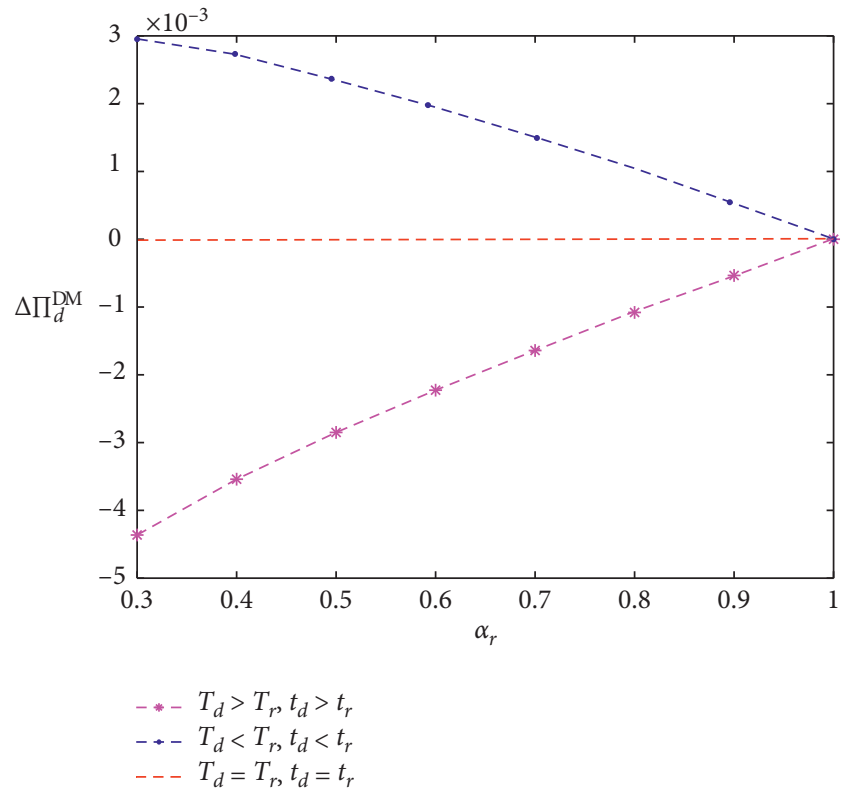

Figure 9: $\Delta \Pi_{d}^{D M}$ change with $\alpha_{r}$.

direct selling profit, the DMBG strategy is more favorable for the manufacturer from the perspective of overall profits.

(iii) When the losses from processing returns in the two channels are equal and the customer return costs in the two channels are equal $\left(T_{d}=T_{r}, t_{d}=t_{r}\right)$, the direct profit, manufacturer's profit, and retailer's profit under the DMBG strategy are no different from those under the MBG strategy.

In summary, the loss from handling returns and the customer return cost in each channel are the main factors that the retailer and manufacturer should consider when deciding which return strategy to choose. Therefore, when the retailer's loss from handling returns and the customer return cost in the retail channel are both lower than the corresponding figures in the direct channel, the retailer and the manufacturer should choose the MBG strategy to achieve a win-win situation. When the manufacturer's loss from handling returns and the customer return cost in the direct channel are both lower than those in the retail channel, the retailer and the manufacturer should choose the DMBG strategy to achieve a win-win situation. To obtain more benefits, the retailer and the manufacturer should reduce the losses from handling returns in their own channels and the customer return cost. In addition, from Figures 7-9, we also find that as customer satisfaction improves, the return rate decreases, and the absolute value of each profit difference also decreases, indicating that high customer satisfaction can offset the impact of both return strategies on the retailer or manufacturer's profit.

\section{O20 Omnichannel Strategy}

In a dual-channel supply chain, manufacturers are more competitive in the market and often dominate; however, is 
the retailer always in a passive position? Retailers can exploit the convenience and advantages of the retail channel and cooperate with manufacturers to establish an $\mathrm{O} 2 \mathrm{O}$ omnichannel. Here, we call this strategy the $\mathrm{O} 2 \mathrm{O}$ omnichannel strategy (abbreviated as $\mathrm{O} 2 \mathrm{O}$ strategy). Under the $\mathrm{O} 2 \mathrm{O}$ strategy, the offline retail channel and the online direct channel form an $\mathrm{O} 2 \mathrm{O}$ omnichannel. The offline retail channel's physical store provides product display and experience services. Notably, to prevent channel conflicts and free riding on customer service, $\mathrm{O} 2 \mathrm{O}$ omnichannels, including offline and online channels, implement the same product price strategy as previously implemented by Apple, Huawei, and $\mathrm{Mi}$. Under the $\mathrm{O} 2 \mathrm{O}$ strategy, the offline retail channel store allows customers to experience the product freely and to perceive the real quality and value of the product to determine whether it meets their requirements and whether to buy it. Moreover, because the perceived experience establishes trust in product quality and value, when the customer chooses to visit the retail channel's physical store, if he is not satisfied with the product, he will forgo purchasing; if he is satisfied with the product, he will purchase in the retail channel's offline physical store, and there will be no return behavior. Moreover, the retail channel can not only enhance the experience and immediacy of the product through the display and experience services but also enable customers to more broadly understand a brand-rich product line, thereby strengthening brand awareness and thus achieving another important taskdraining the online channel into the offline channel to introduce and encourage the purchase of more products by customers. Taking Mi in China as an example, it divides the $\mathrm{O} 2 \mathrm{O}$ omnichannel into three layers from top to bottom, namely, "Mijia Youpin" and "Mi Mall" and "Mi Fans Club." "Mijia Youpin" is an online platform for crowdfunding and screening of popular products and offers with the largest number of products, approximately 20,000 different kinds. "Mi Mall" is also an online e-commerce platform, mainly selling Mi's own-brand products and Mi ecological chain products and offers a moderate number of products, approximately 2,000 different kinds. An offline "Mi Fans Club" physical store, however, can only sell approximately 200 kinds of products due to space restrictions. Through online and offline channels, $\mathrm{Mi}$ can encourage its customers to immediately experience and purchase popular products in offline physical stores; if the product is not available in the physical store, customers can purchase it through the online e-commerce platform. Thus, a customer who visits the physical store once has an opportunity to become a true fan of $\mathrm{Mi}$ and purchase other products from Mi's product line.

Under the $\mathrm{O} 2 \mathrm{O}$ strategy, manufacturers' profits should not be limited to product sales, and more profits can be derived from Internet services, including cloud services, financing, and advertising. For example, the surveillance cameras sold by the Mi manufacturers can not only obtain corresponding profits from sales but also obtain a larger profit from Mi's cloud service including cloud synchronous backup and storage for surveillance video, among other services.
However, experiencing products in the offline physical store involves trouble and inconvenience costs for customers, including time costs. Similar to the study conducted by Cao et al. [46], we use $h$ to denote the trouble cost or inconvenience cost of a customer visiting an offline physical store and experiencing a product under the $\mathrm{O} 2 \mathrm{O}$ strategy. Therefore, under the $\mathrm{O} 2 \mathrm{O}$ strategy, the customer's expected net utility from the physical store (the retail channel) is $U_{r}^{O}=a_{r}(v-p)-h$. When the customer chooses to purchase the product directly on the direct channel without visiting the physical retail channel store, due to the lack of actual experience with the product, there may be return behavior due to product dissatisfaction, and the expected utility of the customer from the direct channel is $U_{d}^{O}=a_{d}(v-p)-\left(1-a_{d}\right) t_{d}$.

By comparing utility functions, we observe that customers have two choices: the customer will choose to buy through the online direct channel if and only if $a_{d}(v-p)-$ $\left(1-a_{d}\right) t_{d} \geq a_{r}(v-p)-h$ and $a_{d}(v-p)-\left(1-a_{d}\right) t_{d} \geq 0$; the customer will choose to buy through the offline retail channel if and only if $a_{r}(v-p)-h \geq a_{d}(v-p)-\left(1-a_{d}\right) t_{d}$ and $a_{r}(v-p)-h \geq 0$. This means that a customer with a utility value in the interval $\left[p+\left(\left(1-\alpha_{d}\right) t_{d} / \alpha_{d}\right), p+((h-\right.$ $\left.\left.\left(1-\alpha_{d}\right) t_{d}\right) /\left(\alpha_{r}-\alpha_{d}\right)\right)$ ] will choose to buy in the online direct channel; a customer with a utility value in the interval $\left[p+\left(\left(h-\left(1-\alpha_{d}\right) t_{d}\right) /\left(\alpha_{r}-\alpha_{d}\right)\right), 1\right]$ will choose to buy in the offline retail channel. Therefore, the effective demands for the offline retail channel and the online direct channel are $D_{r}^{O}=\left[1-p-\left(h-\left(1-\alpha_{d}\right) t_{d} /\left(\alpha_{r}-\alpha_{d}\right)\right)\right]$ and $D_{d}^{O}=\left[\left(h-\left(1-\alpha_{d}\right) t_{d} /\left(\alpha_{r}-\alpha_{d}\right)\right)-\left(h / \alpha_{r}\right)\right]$, respectively.

Under the $\mathrm{O} 2 \mathrm{O}$ strategy, the retailer's profit is $\Pi_{r}^{O}=\max _{p} \alpha_{r}(p-w) D_{r}^{O}$.

The manufacturer's profits include not only sales profits but also Internet service profits. We use a functional form similar to that used in previous studies to express the Internet service profit (e.g., $[47,48])$. The expression of the Internet service profit is $f=(1 / 2) \eta\left(D_{r}^{O}+D_{d}^{O}\right)^{2}$, where $\eta$ is the unit Internet profit conversion rate. Therefore, the manufacturer's profit is as follows:

$$
\begin{aligned}
\Pi_{d}^{O} & =\max _{w} w D_{r}^{O}+\left[\alpha_{d} p-\left(1-\alpha_{d}\right) T_{d}\right] D_{d}^{O}+f \\
& =\max _{w} w D_{r}^{O}+\left[\alpha_{d} p-\left(1-\alpha_{d}\right) T_{d}\right] D_{d}^{O}+\frac{1}{2} \eta\left(D_{r}^{O}+D_{d}^{O}\right)^{2} .
\end{aligned}
$$

We also use a Stackelberg game to obtain the equilibrium solution; the manufacturer dominates and has complete information. The order of the game is as follows. The manufacturer first decides the wholesale price $w$ and then the retailer decides the retail price $p$. The direct channel and the retail channel adopt the same product price strategy; that is, the manufacturer obeys the sales price set by the retailer. Finally, the customer decides whether and where to buy. Proposition 9 can be obtained through backward induction.

Proposition 9. Under the $\mathrm{O} 2 \mathrm{O}$ strategy, the optimal price and wholesale price for the retailer and the manufacturer are 


$$
\begin{aligned}
& p^{O}=\frac{3 \alpha_{r}-\eta-t_{d} \eta-h}{4 \alpha_{r}-\eta}+\frac{t_{d} \eta\left(\alpha_{r}-\alpha_{d}\right)-2 \alpha_{d} \alpha_{r}\left(h-t_{d}+\alpha_{d} t_{d}\right)}{\alpha_{d}\left(\alpha_{r}-\alpha_{d}\right)\left(4 \alpha_{r}-\eta\right)} \\
& w^{O}=\frac{2 \alpha_{r}-\eta-2 h}{4 \alpha_{r}-\eta}+\frac{t_{d} \eta\left(1-\alpha_{d}\right)\left(2 \alpha_{r}-\alpha_{d}\right)+\alpha_{d} \eta h}{\alpha_{d}\left(\alpha_{r}-\alpha_{d}\right)\left(4 \alpha_{r}-\eta\right)} .
\end{aligned}
$$

The proof of Proposition 9 is shown in Appendix A.

Similarly, we denote the demand in the direct channel and in the retail channel under the $\mathrm{O} 2 \mathrm{O}$ strategy as $D_{d}^{O}$ and $D_{r}^{O}$, respectively. The profits of the manufacturer and the retailer are $\Pi_{d}^{O}$ and $\Pi_{r}^{O}$, respectively. For the sake of later analysis, we denote the manufacturer's profit without the Internet service profit as $\Pi_{d}^{O^{\prime}}$, where $\Pi_{d}^{O^{\prime}}=\Pi_{d}^{O}-f$.

Table 7 shows the impact of various parameters on the price, demand, and profit of the retailer and manufacturer under the $\mathrm{O} 2 \mathrm{O}$ strategy. We found the following. (i) As costs faced by retail channel customers visiting the experience store increase, the retailer will lower its sales price and the manufacturer will lower the wholesale price. This means that as the cost that customers face from visiting the experience store increases, the retailer will implement a low-price strategy to attract customers to purchase products and avoid the risk of loss of demand; moreover, the manufacturer will also reduce the wholesale price to mitigate the impact of the low-price strategy on the loss of sales profits from the retailer. (ii) However, as the customer return cost in the direct channel increases, more customers focus on the retail channel, the demand for the direct channel decreases, the demand for the retail channel increases, and the sales price increases, but the manufacturer does not raise the wholesale price. (iii) When the unit Internet profit conversion rate $\eta$ increases, the sales price and the wholesale price both decline, and the demand for the retail channel increases. This shows that as the profit from the Internet service increases, the manufacturer and the retailer directly give back to the customer, by lowering the sales price, more customers are willing to participate in the retailer channel, and the demand for the retail channel increases.

In addition, we also found that under the $\mathrm{O} 2 \mathrm{O}$ strategy, customer satisfaction in the retail channel has a positive impact on the sales price, while customer satisfaction in the direct channel has a negative impact on the sales price. This is because the retail channel and the direct channel implement the same product price strategy, and the sales price is determined by the retail channel, while the direct sales channel obeys the sales price set in the retail channel. Thus, when customer satisfaction with the retail channel increases, the retailer will increase the sales price. When customer satisfaction with the direct channel increases, the demand for the direct channel increases, so that the demand for the retail channel decreases, and the retailer will lower the sales price to encourage more customers to visit the retail store to compensate for the further loss of demand.

\section{O20 Strategy and Return Strategy Selection}

In practice, retailers and manufacturers mostly base their strategy choices using profit-based analysis. Therefore, we will discuss the impact of the $\mathrm{O} 2 \mathrm{O}$ strategy on the retailer and the manufacturer's profits and perform a comparative analysis of the MBG and DMBG strategies mentioned above, analyze whether the retailer and the manufacturer are willing to cooperate on the $\mathrm{O} 2 \mathrm{O}$ strategy, and extract further managerial insights. Due to the complexity of the retailer and manufacturer's profit functions under the $\mathrm{O} 2 \mathrm{O}$ strategy, we have to use numerical simulation in our analysis.

5.1. Retailer's Strategy Selection. In view of the previous analysis, we know that the MBG strategy is more beneficial to the retailer than the DMBG strategy because the retailer's loss from handling returns and the customer return cost are both lower $\left(T_{r}<T_{d}, t_{r}<t_{d}\right)$. Therefore, for the analysis of the retailer's strategic choice, we will only compare the $\mathrm{O} 2 \mathrm{O}$ strategy with the MBG strategy and consider whether the retailer is more inclined to the MBG strategy or the $\mathrm{O} 2 \mathrm{O}$ strategy. Can the $\mathrm{O} 2 \mathrm{O}$ strategy improve the retailer's profit? We define $\Delta \Pi_{r}^{O}=\Pi_{r}^{O}-\Pi_{r}^{M}$ to represent the impact of the $\mathrm{O} 2 \mathrm{O}$ strategy on the retailer's profit based on the MBG strategy.

Observation 1. The $\mathrm{O} 2 \mathrm{O}$ strategy can effectively increase the profitability of the retailer, and the retailer always tends to choose the $\mathrm{O} 2 \mathrm{O}$ strategy.

From Figures 10-12, we find the following.

(i) As customer satisfaction in the retail channel increases, the effectiveness of the $\mathrm{O} 2 \mathrm{O}$ strategy will have a more substantial positive effect on the retailer's profit. However, costs faced by customers in accessing the physical store will inhibit the feasibility of the retailer participating in the implementation of the $\mathrm{O} 2 \mathrm{O}$ strategy. That is, as such costs increase, the positive profit difference, $\Delta \Pi_{r}^{O}$ will decrease (Figure 10).

(ii) As the retailer's loss from handling returns $T_{r}$ increases, the retailer is more inclined to implement the $\mathrm{O} 2 \mathrm{O}$ strategy. This is because as the retailer's loss from handling returns $T_{r}$ increases, the profit earned by the retailer under the MBG strategy is reduced. However, when the retailer implements the $\mathrm{O} 2 \mathrm{O}$ strategy, because the customer can experience the product in the physical store, if the product is satisfactory, then no returns are made. Therefore, when the retailer implements the $\mathrm{O} 2 \mathrm{O}$ strategy, it has nothing to do with $T_{r}$. Therefore, as the retailer's loss from handling returns increases, the retailer's profit from the implementation of MBG declines, and the retailer is more inclined to choose the $\mathrm{O} 2 \mathrm{O}$ strategy. Similarly, the retailer is also more inclined to implement the $\mathrm{O} 2 \mathrm{O}$ strategy as the customer return cost $t_{r}$ in the retail channel increases. This means that as the retailer's loss from handling returns $T_{r}$ and the customer return cost $t_{r}$ in the retail channel increase, the $\mathrm{O} 2 \mathrm{O}$ strategy is more effective at increasing the retailer's profit (Figure 11). 
TABLe 7: Sensitivity analysis of equilibrium demand, price, and profit under the $\mathrm{O} 2 \mathrm{O}$ strategy.

\begin{tabular}{lccccccccc}
\hline & $p^{O}$ & $w^{O}$ & $D_{r}^{O}$ & $D_{d}^{O}$ & $\Pi_{r}^{O}$ & $\Pi_{d 1}^{O}$ & $\Pi_{d 2}^{O}$ & $f$ & $\Pi_{d}^{O}$ \\
\hline$\alpha_{r}$ & $\uparrow$ & $\uparrow$ & $\uparrow$ & $\downarrow$ & $\uparrow$ & $\uparrow$ & $\downarrow$ & $\downarrow$ & $\uparrow$ \\
$\alpha_{d}$ & $\downarrow$ & $\downarrow$ & $\downarrow$ & $\uparrow$ & $\downarrow$ & $\downarrow$ & $\uparrow$ & $\uparrow$ & $\uparrow$ \\
$h$ & $\downarrow$ & $\downarrow$ & $\downarrow$ & $\uparrow$ & $\downarrow$ & $\downarrow$ & $\uparrow$ & $\uparrow$ & $\uparrow$ \\
$T_{d}$ & - & - & - & - & - & - & $\downarrow$ & - & $\downarrow$ \\
$t_{d}$ & $\uparrow$ & $\uparrow$ & $\uparrow$ & $\downarrow$ & $\uparrow$ & $\uparrow$ & $\downarrow$ & $\downarrow$ (micro) & $\downarrow$ \\
$\eta$ & $\downarrow$ & $\downarrow$ & $\uparrow$ & - & $\uparrow$ & $\uparrow$ & $\downarrow$ & $\uparrow$ & $\uparrow$ \\
\hline
\end{tabular}

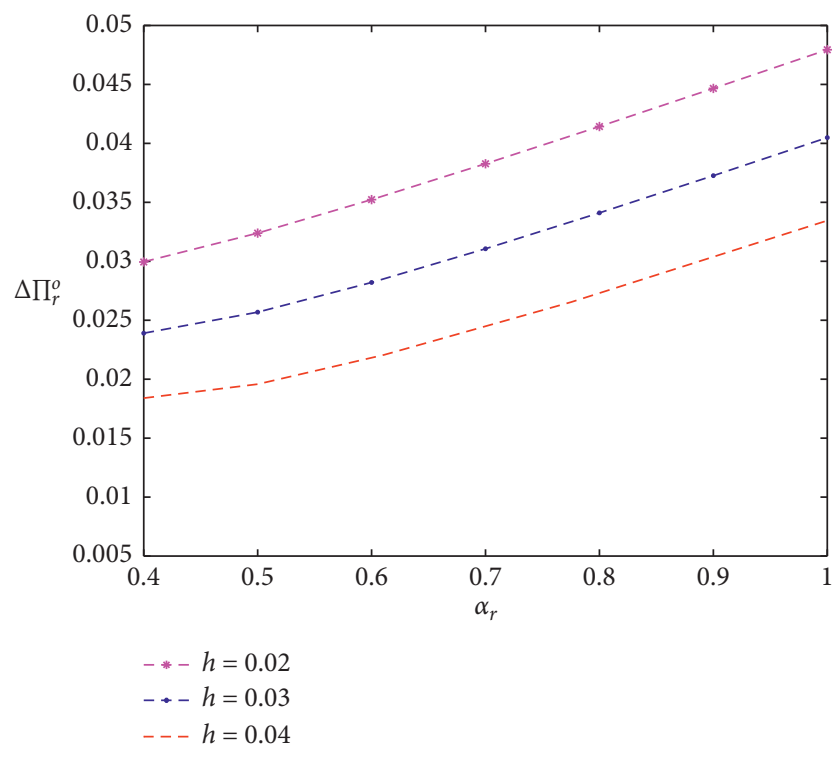

Figure 10: $\Delta \Pi_{r}^{O}$ change with $\alpha_{r}$ and $h$.

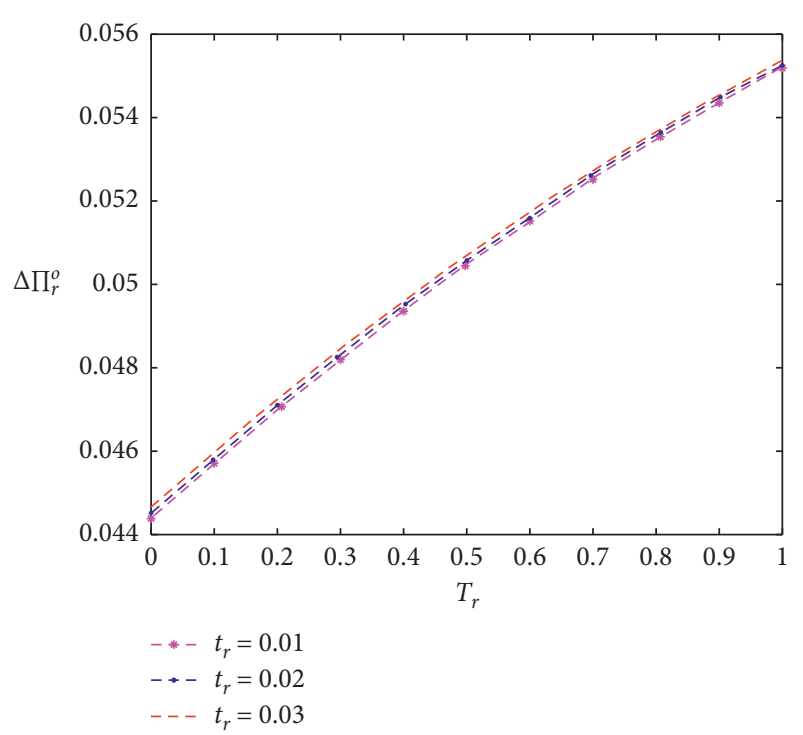

FIgURE 11: $\Delta \Pi_{r}^{O}$ change with $T_{r}$ and $t_{r}$.

(iii) As the manufacturer's loss from handling returns $T_{d}$ increases, the effectiveness of the $\mathrm{O} 2 \mathrm{O}$ strategy becomes less effective at boosting the retailer's profit. This is because as the manufacturer's loss

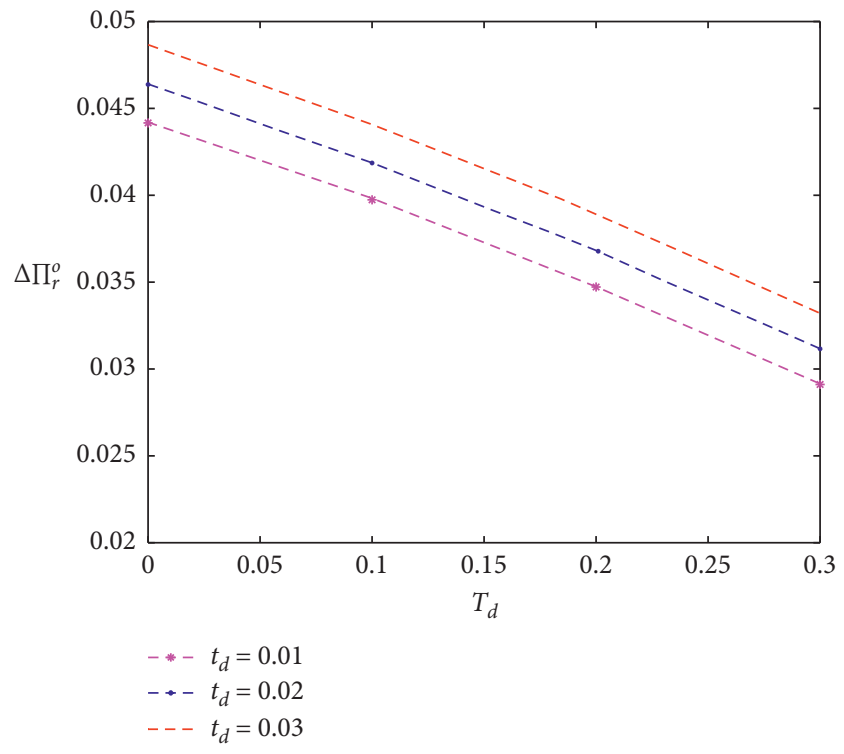

Figure 12: $\Delta \Pi_{r}^{O}$ change with $T_{d}$ and $t_{d}$.

from handling returns $T_{d}$ increases, the profit from the retailer's implementation of the MBG strategy will gradually increase and the profit from the retailer's implementation of $\mathrm{O} 2 \mathrm{O}$ strategy will not be affected by $T_{d}$. Therefore, an increase in $T_{d}$ will weaken the retailer's willingness to choose the $\mathrm{O} 2 \mathrm{O}$ strategy. However, as the customer return cost $t_{d}$ in the direct channel increases, the $\mathrm{O} 2 \mathrm{O}$ strategy will become more effective at increasing the retailer's profit. This is because as the customer return cost in the direct channel increases, the profit obtained from the retailer's implementation of the $\mathrm{O} 2 \mathrm{O}$ strategy increases faster than that under the MBG strategy, resulting in a greater difference in positive profit $\Delta \Pi_{r}^{O}$ and more significant effectiveness of the $\mathrm{O} 2 \mathrm{O}$ strategy to improve the retailer's profit (Figure 12).

Interestingly, from Figures 10-12, we always find that the profit difference $\Delta \Pi_{r}^{O}$ is always greater than zero. This means that the retailer would be actually more willing to choose to implement the $\mathrm{O} 2 \mathrm{O}$ strategy.

5.2. Manufacturer's Strategy Selection. In the same way, we know that, in the case of $T_{r}<T_{d}$ and $t_{r}<t_{d}$, the 


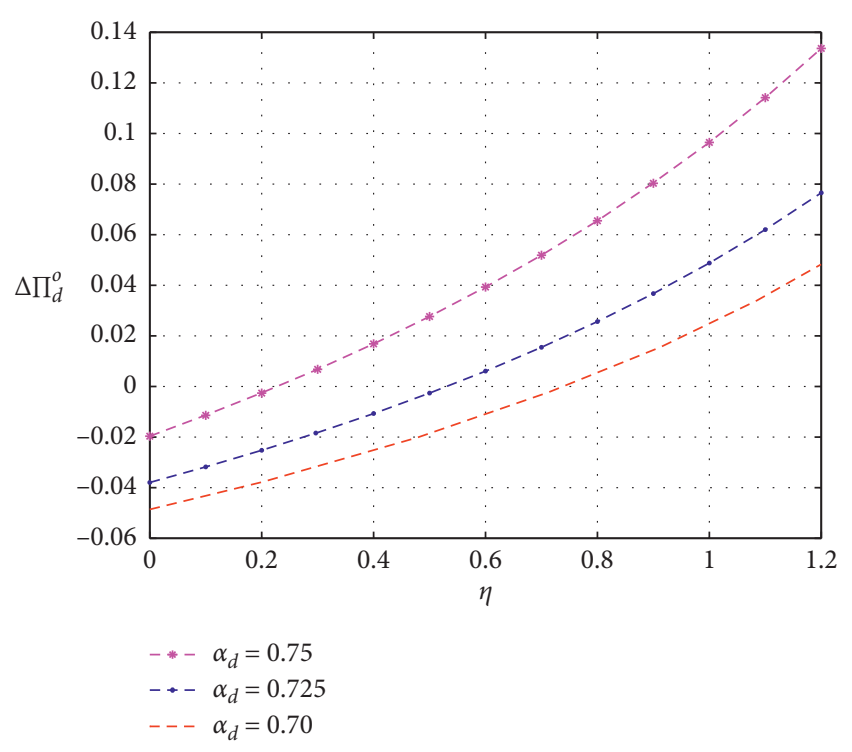

Figure 13: $\Delta \Pi_{d}^{O}$ change with $\eta$ and $\alpha_{d}$.

manufacturer also chooses the MBG strategy over the DMBG strategy given the effects on overall profits. Therefore, for the manufacturer's strategic choice analysis, we will also compare the $\mathrm{O} 2 \mathrm{O}$ strategy with the $\mathrm{MBG}$ strategy, considering whether the manufacturer is more inclined to the MBG strategy or the $\mathrm{O} 2 \mathrm{O}$ strategy. Can the $\mathrm{O} 2 \mathrm{O}$ strategy improve the manufacturer's profit? Similarly, we define $\Delta \Pi_{d}^{O}=\Pi_{d}^{O}-\Pi_{d}^{M}$ to represent the impact of the $\mathrm{O} 2 \mathrm{O}$ strategy on the manufacturer's profit relative to the MBG strategy.

Observation 2. When $\eta>\arg \left[f(\eta)>\max \left\{\left(\Pi_{d}^{M}-\Pi_{d}^{O^{\prime}}\right), 0\right\}\right]$, which is $f(\eta)>\max \left\{\left(\Pi_{d}^{M}-\Pi_{d}^{O^{\prime}}\right), 0\right\}$, the manufacturer would be willing to integrate online and offline channels to implement the $\mathrm{O} 2 \mathrm{O}$ strategy.

From Figure 13, we find that (i) when the unit Internet profit conversion rate $\eta$ is greater than a certain threshold $\arg \left[f(\eta)>\max \left\{\left(\Pi_{d}^{M}-\Pi_{d}^{O^{\prime}}\right), 0\right\}\right]$, the profit of the manufacturer from implementing the $\mathrm{O} 2 \mathrm{O}$ strategy is greater than that from implementing the MBG strategy. Furthermore, when the manufacturer implements the $\mathrm{O} 2 \mathrm{O}$ strategy when the profit from the Internet service is greater than the loss from switching from the MBG strategy to the $\mathrm{O} 2 \mathrm{O}$ strategy, the manufacturer is willing to integrate the online and offline channels and implement the $\mathrm{O} 2 \mathrm{O}$ strategy.

In summary, we conclude that if the offline channel can fully drain the online channel, that is, the manufacturer's Internet service profit from implementing the $\mathrm{O} 2 \mathrm{O}$ strategy is greater than a certain threshold, such as $f>\max \left\{\left(\Pi_{d}^{M}-\Pi_{d}^{O^{\prime}}\right), 0\right\} \quad$ or $\quad \eta>\arg \left[f(\eta)>\max \left\{\left(\Pi_{d}^{M-}\right.\right.\right.$ $\left.\left.\left.\Pi_{d}^{O^{\prime}}\right), 0\right\}\right]$, the manufacturer would be willing to integrate the online and offline channels and implement the $\mathrm{O} 2 \mathrm{O}$ strategy.

\section{Conclusions}

This paper studies the problems of pricing decisions and strategy choices of a retailer and a manufacturer with a direct channel in a dual-channel supply chain, with a focus on the single and dual versions of the MBG and the newly popular $\mathrm{O} 2 \mathrm{O}$ omnichannel strategy. Our analysis provides new insights into the return strategy selection of the retailer and the manufacturer, the integration of $\mathrm{O} 2 \mathrm{O}$ channels, and the pricing decisions of two competitive channels. In particular, we show that when the retailer and manufacturer have not cooperated to establish an $\mathrm{O} 2 \mathrm{O}$ channel, the retailer is reluctant to choose the DMBG strategy and prefers the MBG strategy if the retailer's loss from handling returns and the customer return cost are both low (i.e., $T_{d}<T_{r}, t_{d}<t_{r}$ ), which contradicts our intuition and is an interesting conclusion. However, when the retailer achieves channel cooperation with the manufacturer, the retailer is always willing to choose the $\mathrm{O} 2 \mathrm{O}$ strategy instead of the MBG or DMBG strategy.

We find that, unlike the situation of retailer's decisionmaking, the manufacturer's decision depends not only on the handling loss and the customer return cost but also on other factors. Specifically, when the manufacturer does not cooperate with the retailer to integrate an $\mathrm{O} 2 \mathrm{O}$ channel, if both the loss from the retailer's handling of returns and her customer return cost are low and the retailer and the manufacturer can effectively handle the customers' returns, the net salvage value of satisfaction is positive. In this case, the DMBG strategy benefits the manufacturer's direct channel, and MBG improves the manufacturer's wholesale profit. This means that if the manufacturer wants to support the direct channel and cultivate the customers of his own direct channel when it is first opened, the manufacturer should consider implementing the DMBG strategy. This strategy can not only rapidly increase the market share and profit of direct marketing channels but also provide MBG services to the retailer to compensate for the retailer's return loss to alleviate channel conflicts caused by opening a direct channel. Conversely, the manufacturer should choose the MBG strategy to achieve a win-win situation.

In another case, when the retailer and manufacturer have not cooperated to establish an $\mathrm{O} 2 \mathrm{O}$ channel and if the manufacturer's loss from handling returns and the customer return cost are both low, the manufacturer and the retailer should choose the DMBG strategy to achieve a win-win situation. In conclusion, our analysis shows that the size of the return loss and the customer return cost of each channel are the main factors that the retailer and the manufacturer should consider when deciding which return strategy to choose when the two channels are not operated cooperatively. The results further provide a theoretical explanation and practical guidance for the popularity of MBG and DMBG observed in the retail industry.

We also show that when considering whether the retailer cooperates with the manufacturer to establish the $\mathrm{O} 2 \mathrm{O}$ strategy, the retailer always tends to cooperate with the manufacturer and establish $\mathrm{O} 2 \mathrm{O}$ omnichannels based on unified pricing, and as customer satisfaction with the retail 
channel and the retailer's handling of return losses increase, the effectiveness of the $\mathrm{O} 2 \mathrm{O}$ strategy in increasing the retailer's profits will be more substantial, while the increase in the manufacturer's losses from handling returns will inhibit the $\mathrm{O} 2 \mathrm{O}$ strategy from increasing the profits of the retailer. However, the manufacturer cannot always benefit from the $\mathrm{O} 2 \mathrm{O}$ strategy; the manufacturer can benefit from the $\mathrm{O} 2 \mathrm{O}$ strategy only when the unit conversion rate of Internet service profit is greater than a certain threshold and the profit of Internet service is higher. This result cautions retailers that if they wish to improve profits via an $\mathrm{O} 2 \mathrm{O}$ strategy, they should ensure that the offline channel can fully drain to the online channel to achieve the goal of establishing the $\mathrm{O} 2 \mathrm{O}$ channel in cooperation with the manufacturer. In a word, our analysis shows that, under certain conditions, retailers adopting an $\mathrm{O} 2 \mathrm{O}$ strategy and the manufacturer adopting an MBG in the direct channel can produce a winwin result.

In the current analysis, we assume that there is no quality difference between the two channels and that the return strategy is a full refund. One extension of this paper would be to consider quality differences between the two channels. Another extension could be to examine the optimal return strategy (full refund, partial refund, or nonrefund strategy) in the dual-channel supply chain and the optimal refund price under the partial refund strategy.

\section{Appendix}

\section{All Proofs}

Proof of Proposition 1.

For a given $p_{d}$ and $w$, taking derivatives of $\Pi_{r}^{N}$ with respect to $p_{r}: \quad\left(\mathrm{d} \prod_{r}^{N} / \mathrm{d} p_{r}\right)=\left(1 /\left(\alpha_{r}-\alpha_{d}\right)\right)\left(\alpha_{r}-\alpha_{d}\right.$ $\left.+p_{d}-2 p_{r}+w\right)$, and $\left(\mathrm{d}^{2} \prod_{r}^{N} / \mathrm{d}\left(p_{r}\right)^{2}\right)=-\left(2 /\left(\alpha_{r}-\alpha_{d}\right)\right)$. With $\left(\mathrm{d}^{2} \prod_{r}^{N} / \mathrm{d}\left(p_{r}\right)^{2}\right)<0$, a unique optimal $p_{\mathrm{r}}$ is

$$
p_{r}=\frac{\alpha_{r}-\alpha_{d}+p_{d}+w}{2} .
$$

By substituting (A.1) into $\Pi_{d}^{N}$, the Hessian matrix is obtained by taking the second partial derivatives of $\Pi_{d}^{N}$ with respect to $p_{d}$ and $w$ :

$$
H_{1}=\left[\begin{array}{cc}
-\frac{2\left(\alpha_{r}-\left(\alpha_{d} / 2\right)\right)}{\alpha_{d}\left(\alpha_{r}-\alpha_{d}\right)} & \frac{1}{\alpha_{r}-\alpha_{d}} \\
\frac{1}{\alpha_{r}-\alpha_{d}} & -\frac{1}{\alpha_{r}-\alpha_{d}}
\end{array}\right]
$$

With $-\left(2\left(\alpha_{r}-\left(\alpha_{d} / 2\right)\right) / \alpha_{d}\left(\alpha_{r}-\alpha_{d}\right)\right)<0$ and $\left|H_{1}\right|=\left(2 / \alpha_{d}\right.$ $\left.\left(\alpha_{r}-\alpha_{d}\right)\right)>0, \Pi_{d}^{N}$ is jointly concave in $p_{d}$ and $w$. Therefore, the unique optimal $p_{d}^{N}$ and $w^{N}$ can be determined by the first-order partial derivatives $\left(\partial \prod_{d}^{N} / \partial p_{d}\right)=0$ and $\left(\partial \prod_{d}^{N} / \partial w\right)=0$.

By substituting $p_{d}^{N}$ and $w^{N}$ into (A.1), the optimal $p_{r}^{N}$ can be obtained. Thus, Proposition 1 is proven.

Proof of Proposition 2.

For a given $p_{d}$ and $w$, taking the second derivative of $\Pi_{r}^{M}$ with respect to $p_{r}, \quad\left(\mathrm{~d}^{2} \prod_{r}^{M} / \mathrm{d}\left(p_{r}\right)^{2}\right)=-\left(2 \alpha_{r}^{2} /\left(\alpha_{r}-\alpha_{d}\right)\right)$.
With $\left(\mathrm{d}^{2} \prod_{r}^{M} / \mathrm{d}\left(p_{r}\right)^{2}\right)<0$, a unique optimal $p_{r}$ can be determined by the first-order derivative $\left(\partial \prod_{r}^{M} / \partial p_{r}\right)=0$.

By substituting the optimal $p_{r}$ into $\Pi_{d}^{M}$, the Hessian matrix is obtained by taking the second partial derivatives of $\Pi_{d}^{M}$ with respect to $p_{d}$ and $w$ :

$$
H_{2}=\left[\begin{array}{cc}
-\frac{2 \alpha_{d} \alpha_{r}\left(1-\left(\alpha_{d} / 2 \alpha_{r}\right)\right)}{\alpha_{r}-\alpha_{d}} & \frac{\alpha_{d}}{\alpha_{r}-\alpha_{d}} \\
\frac{\alpha_{d}}{\alpha_{r}-\alpha_{d}} & -\frac{1}{\alpha_{r}-\alpha_{d}}
\end{array}\right] .
$$

With $-\left(\left(2 \alpha_{d} \alpha_{r}\left(1-\left(\alpha_{d} / 2 \alpha_{r}\right)\right)\right) /\left(\alpha_{r}-\alpha_{d}\right)\right)<0$ and $\left|H_{2}\right|=$ $\left(2 \alpha_{d} / \alpha_{d}\left(\alpha_{r}-\alpha_{d}\right)\right)>0, \Pi_{d}^{M}$ is jointly concave in $p_{d}$ and $w$. Therefore, the unique optimal $p_{d}^{M}$ and $w^{M}$ can be determined by the first-order partial derivatives $\left(\partial \prod_{d}^{M} / \partial p_{d}\right)=0$ and $\left(\partial \prod_{d}^{M} / \partial w\right)=0$.

By substituting $p_{d}^{M}$ and $w^{M}$ into $p_{r}$, the optimal $p_{r}^{M}$ can be obtained. Thus, Proposition 2 is proven.

Proof of Proposition 3

(i) We have

$$
\begin{aligned}
p_{r}^{M}-p_{r}^{N}= & \frac{1}{4 \alpha_{r}}\left[3 \alpha_{r}\left(1-\alpha_{r}\right)-3 t_{r}\left(1-\alpha_{r}\right)+T_{d}\left(1-\alpha_{d}\right)\right. \\
& \left.+T_{r}\left(1-\alpha_{r}\right)+t_{d}\left(1-\alpha_{d}\right)-\alpha_{d}\left(1-\alpha_{r}\right)\right] \\
> & \frac{1}{4 \alpha_{r}}\left[3 \alpha_{r}\left(1-\alpha_{r}\right)-3 t_{r}\left(1-\alpha_{r}\right)+2 T_{r}\left(1-\alpha_{r}\right)\right. \\
& \left.+t_{r}\left(1-\alpha_{r}\right)-\alpha_{r}\left(1-\alpha_{r}\right)\right] \\
= & \frac{1}{2 \alpha_{r}}\left(1-\alpha_{r}\right)\left(T_{r}+\alpha_{r}-t_{r}\right) .
\end{aligned}
$$

Because $t_{r}<T_{r}$, therefore, $p_{r}^{M}>p_{r}^{N}$.

(ii) We have $p_{d}^{M}-p_{d}^{N}=\left(1 / 2 \alpha_{d}\right)\left(1-\alpha_{d}\right)\left(T_{d}+\alpha_{d}-t_{d}\right)$. Because $t_{d}<T_{d}$, therefore, $p_{d}^{M}>p_{d}^{N}$.

(iii) We have $w^{M}-w^{N}=-(1 / 2)\left(1-\alpha_{r}\right)\left(T_{r}+t_{r}\right)<0$; therefore, $w^{M}<w^{N}$.

Proof of Proposition 4.

(i)

$$
\begin{aligned}
D_{r}^{M}-D_{r}^{N}= & \frac{1}{4\left(\alpha_{r}-\alpha_{d}\right)}\left(T_{d}-T_{r}+t_{d}-t_{r}-\alpha_{d} T_{d}+\alpha_{r} T_{r}\right. \\
& \left.-\alpha_{d} t_{d}+\alpha_{r} t_{r}\right) \\
> & \frac{1}{4\left(\alpha_{r}-\alpha_{d}\right)}\left(T_{d}-T_{r}+t_{d}-t_{r}-\alpha_{d} T_{d}+\alpha_{d} T_{r}\right. \\
& \left.-\alpha_{d} t_{d}+\alpha_{d} t_{r}\right) \\
= & \frac{1}{4\left(\alpha_{r}-\alpha_{d}\right)}\left(1-\alpha_{d}\right)\left(T_{d}+t_{d}-T_{r}-t_{r}\right)>0 .
\end{aligned}
$$


(ii) We can obtain

When $T_{d}+t_{d}>T_{r}+t_{r}$, we can obtain $D_{r}^{M}>D_{r}^{N}$.

$$
\prod_{r}^{M}-\prod_{r}^{N}=\frac{1}{16\left(\alpha_{r}-\alpha_{d}\right)}[\underbrace{\left[\left(\alpha_{r}-\alpha_{d}\right)+T_{d}-T_{r}+t_{d}-t_{r}-\left(\alpha_{d} T_{d}-\alpha_{r} T_{r}\right)-\left(\alpha_{d} t_{d}-\alpha_{r} t_{r}\right)\right]}_{(1)} \underbrace{2}_{(2)} \underbrace{\left(\alpha_{2}\right)}_{\left(\alpha_{r}-\alpha_{d}\right)} \text {. }
$$

When $T_{d}+t_{d}>T_{r}+t_{r}$, part (1) is strictly greater than part (2); that is,

$$
\begin{aligned}
& \left(\alpha_{r}-\alpha_{d}\right)+T_{d}-T_{r}+t_{d}-t_{r}-\left(\alpha_{d} T_{d}-\alpha_{r} T_{r}\right)-\left(\alpha_{d} t_{d}-\alpha_{r} t_{r}\right) \\
& >\left(\alpha_{r}-\alpha_{d}\right)+T_{d}-T_{r}+t_{d}-t_{r}-\alpha_{d}\left(T_{d}-T_{r}\right)-\alpha_{d}\left(t_{d}-t_{r}\right) \\
& =\left(\alpha_{r}-\alpha_{d}\right)+\left(1-\alpha_{d}\right)\left(T_{d}+t_{d}-T_{r}-t_{r}\right)>\left(\alpha_{r}-\alpha_{d}\right) .
\end{aligned}
$$

Therefore, when $T_{d}+t_{d}>T_{r}+t_{r}$, we can obtain $\prod_{r}^{M}>\prod_{r}^{N}$.

Proof of Proposition 5.

$$
\begin{aligned}
D_{d}^{M}-D_{d}^{N} & =\frac{1}{4 \alpha_{d}\left(\alpha_{r}-\alpha_{d}\right)}\left[\alpha_{d}\left(1-\alpha_{r}\right)\left(T_{r}+t_{r}\right)-\alpha_{r}\left(1-\alpha_{d}\right)\left(T_{d}+t_{d}\right)-\left(\alpha_{r}-\alpha_{d}\right)\left(1-\alpha_{d}\right)\left(T_{d}+t_{d}\right)\right] \\
& \leq-\frac{1}{4 \alpha_{d}\left(\alpha_{r}-\alpha_{d}\right)}\left[\alpha_{r}\left(1-\alpha_{d}\right)\left(T_{d}+t_{d}-T_{r}-t_{r}\right)+\left(\alpha_{r}-\alpha_{d}\right)\left(1-\alpha_{d}\right)\left(T_{d}+t_{d}\right)\right] .
\end{aligned}
$$

When $T_{d}+t_{d}>T_{r}+t_{r}$, we have $D_{d}^{M}-D_{d}^{N}<0$; that is,

$D_{d}^{M}<D_{d}^{N}$.

$\prod_{d 2}^{M}-\prod_{d 2}^{N}$

$$
\begin{aligned}
& =\frac{1}{8 \alpha_{d}\left(\alpha_{r}-\alpha_{d}\right)}\left\{\left[\alpha_{d}-\left(1-\alpha_{d}\right)\left(T_{d}+t_{d}\right)\right)\right]\left[\alpha_{d}\left(\alpha_{r}-\alpha_{d}\right)-2 \alpha_{r}\left(1-\alpha_{d}\right)\left(T_{d}+t_{d}\right)+\alpha_{d}\left(1-\alpha_{r}\right)\left(T_{r}+t_{r}\right)\right. \\
& \left.\left.\quad+\alpha_{d}\left(1-\alpha_{d}\right)\left(T_{d}+t_{d}\right)\right]-\alpha_{d}\left[\alpha_{d}\left(\alpha_{r}-\alpha_{d}\right)\right]\right\} \\
& \leq \frac{1}{8 \alpha_{d}\left(\alpha_{r}-\alpha_{d}\right)}\left\{[ \alpha _ { d } - ( 1 - \alpha _ { d } ) ( T _ { d } + t _ { d } ) ] \left[\alpha_{d}\left(\alpha_{r}-\alpha_{d}\right)-2 \alpha_{d}\left(1-\alpha_{d}\right)\left(T_{d}+t_{d}\right)+\alpha_{d}\left(1-\alpha_{d}\right)\left(T_{r}+t_{r}\right)\right.\right. \\
& \left.\left.\quad+\alpha_{d}\left(1-\alpha_{d}\right)\left(T_{d}+t_{d}\right)\right]-\alpha_{d}\left[\alpha_{d}\left(\alpha_{r}-\alpha_{d}\right)\right]\right\} \\
& =\frac{1}{8 \alpha_{d}\left(\alpha_{r}-\alpha_{d}\right)}\{\underbrace{\left[\alpha_{d}-\left(1-\alpha_{d}\right)\left(T_{d}+t_{d}\right)\right]\left[\alpha_{d}\left(\alpha_{r}-\alpha_{d}\right)-\alpha_{d}\left(1-\alpha_{d}\right)\left(T_{d}+t_{d}-T_{r}-t_{r}\right)\right]}_{(1)}-\underbrace{\alpha_{d}\left[\alpha_{d}\left(\alpha_{r}-\alpha_{d}\right)\right]}_{(2)}\} .
\end{aligned}
$$


When $T_{d}+t_{d}>T_{r}+t_{r}$, part (1) is strictly less than part (2); that is, $\prod_{d 2}^{M}<\prod_{d 2}^{N}$.

(ii)

$$
\begin{aligned}
\prod_{d 1}^{M}-\prod_{d 1}^{N}= & \frac{1}{16\left(\alpha_{r}-\alpha_{d}\right)}\left\{2\left[\alpha_{r}-\left(1-\alpha_{r}\right)\left(T_{r}+t_{r}\right)\right]\right. \\
& \left(T_{d}-T_{r}-\alpha_{d}+\alpha_{r}+t_{d}-t_{r}-T_{d} \alpha_{d}\right. \\
& \left.\left.+T_{r} \alpha_{r}-\alpha_{d} t_{d}+\alpha_{r} t_{r}\right)-\left(\alpha_{r}-\alpha_{d}\right)^{2}\right\} \\
> & \frac{1}{16\left(\alpha_{r}-\alpha_{d}\right)}\left\{\left[\alpha_{r}-\left(1-\alpha_{r}\right)\left(T_{r}+t_{r}\right)\right]\right. \\
& {\left.\left[\left(\alpha_{r}-\alpha_{d}\right)+\left(1-\alpha_{d}\right)\left(T_{d}+t_{d}-T_{r}-t_{r}\right)\right]-\left(\alpha_{r}-\alpha_{d}\right)^{2}\right\} . }
\end{aligned}
$$

Apparently, when $T_{d}+t_{d}>T_{r}+t_{r}$ and $\alpha_{r}-\left(1-\alpha_{r}\right)$ $\left(T_{r}+t_{r}\right)>\alpha_{r}-\alpha_{d}$, we have $\prod_{d 1}^{M}>\prod_{d 1}^{N}$. By $\alpha_{r}>\alpha_{d}$, when $T_{d}+t_{d}>T_{r}+t_{r}$ and $\alpha_{r}>\left(1-\alpha_{r}\right)\left(T_{r}+t_{r}\right)$, we can obtain $\prod_{d 1}^{M}>\prod_{d 1}^{N}$.

Proof of Proposition 6.

For a given $p_{d}$ and $w$, taking the second derivative of $\Pi_{r}^{M}$ with respect to $\mathrm{pr},\left(\mathrm{d}^{2} \prod_{r}^{D M} / \mathrm{d}\left(p_{r}\right)^{2}\right)=-\left(2 \alpha_{r}^{2} /\left(\alpha_{r}-\alpha_{d}\right)\right)$. With $\left(\mathrm{d}^{2} \prod_{r}^{D M} / \mathrm{d}\left(p_{r}\right)^{2}\right)<0$, a unique optimal pr can be determined by the first-order derivative $\left(\partial \prod_{r}^{D M} / \partial p_{r}\right)=0$. By substituting the optimal $p_{r}$ into $\Pi_{d}^{D M}$, the Hessian matrix is obtained by taking the second partial derivatives of $\Pi_{d}^{D M}$ with respect to $p_{d}$ and $w$ :

$$
H_{3}=\left[\begin{array}{cc}
-\frac{2 \alpha_{d} \alpha_{r}\left(1-\left(\alpha_{d} / 2 \alpha_{r}\right)\right)}{\alpha_{r}-\alpha_{d}} & \frac{\alpha_{d} \alpha_{r}}{\alpha_{r}-\alpha_{d}} \\
\frac{\alpha_{d} \alpha_{r}}{\alpha_{r}-\alpha_{d}} & -\frac{\alpha_{r}^{2}}{\alpha_{r}-\alpha_{d}}
\end{array}\right] .
$$

With $\quad-\left(2 \alpha_{d} \alpha_{r}\left(1-\left(\alpha_{d} / 2 \alpha_{r}\right)\right) /\left(\alpha_{r}-\alpha_{d}\right)\right)<0 \quad$ and $\left|H_{3}\right|=\left(2 \alpha_{d} \alpha_{r}^{2} /\left(\alpha_{r}-\alpha_{d}\right)\right)>0, \Pi_{d}^{D M}$ is jointly concave in $p_{d}$ and $w$. Therefore, the unique optimal $p_{d}^{D M}$ and $w^{D M}$ can be determined by the first-order partial derivatives $\left(\partial \prod_{d}^{D M} / \partial p_{d}\right)=0$ and $\left(\partial \prod_{d}^{D M} / \partial w\right)=0$.

By substituting $p_{d}^{D M}$ and $w^{D M}$ into $p_{r}$, the optimal $p_{r}^{D M}$ can be obtained. Thus, Proposition 9 is proven.

Proof of Proposition 7.

(i) $p_{r}^{D M}-p_{r}^{M}=\left(1 / 4 \alpha_{r}\right)\left(1-\alpha_{r}\right)\left(T_{d}-T_{r}\right)$. When $T_{d}>$ $T_{r}$, we have $p_{r}^{D M}>p_{r}^{M}$.

(ii) $p_{d}^{D M}-p_{d}^{M}=0$. $w^{D M}-w^{M}=\left(1 / 2 \alpha_{r}\right)\left(1-\alpha_{r}\right)\left(\alpha_{r}+\right.$ $\left.T_{d}-t_{r}+\alpha_{r} T_{r}+\alpha_{r} t_{r}\right)$, due to $T_{d}>t_{r}, w^{D M}-w^{M}>0$.

Proof of Proposition 8.

(i) $D_{r}^{D M}-D_{r}^{M}=-\left(1 / 4\left(\alpha_{r}-\alpha_{d}\right)\right)\left(1-\alpha_{r}\right)\left(T_{d}-T_{r}\right)$. When $T_{d}^{r}>T_{r}$, we can obtain $D_{r}^{D M}<D_{r}^{M}$. $D_{d}^{D M}-D_{d}^{M}=\left(1 / 4\left(\alpha_{r}-\alpha_{d}\right)\right)\left(1-\alpha_{r}\right)\left(T_{d}-T_{r}\right)$. When $T_{d}>T_{r}$, we can obtain $D_{d}^{D M}>D_{d}^{M}$.

(ii)

$$
\begin{aligned}
\Pi_{r}^{D M}-\Pi_{r}^{M} & =\frac{1}{16\left(\alpha_{r}-\alpha_{d}\right)}\left(1-\alpha_{r}\right)\left(T_{d}-T_{r}\right)\left(T_{r}-T_{d}+2 \alpha_{d}-2 \alpha_{r}-2 t_{d}+2 t_{r}+2 \alpha_{d} T_{d}-\alpha_{r} T_{d}-\alpha_{r} T_{r}+2 \alpha_{d} t_{d}-2 \alpha_{r} t_{r}\right) \\
& <\frac{1}{16\left(\alpha_{r}-\alpha_{d}\right)}\left(1-\alpha_{r}\right)\left(T_{d}-T_{r}\right)\left(T_{r}-T_{d}+2 \alpha_{d}-2 \alpha_{r}-2 t_{d}+2 t_{r}+2 \alpha_{d} T_{d}-\alpha_{d} T_{d}-\alpha_{d} T_{r}+2 \alpha_{r} t_{d}-2 \alpha_{r} t_{r}\right) \\
& =\frac{1}{16\left(\alpha_{r}-\alpha_{d}\right)}\left(1-\alpha_{r}\right)\left(T_{d}-T\right)_{r}\left[-2\left(\alpha_{r}-\alpha_{d}\right)-\left(1-\alpha_{d}\right)\left(T_{d}-T\right)_{r}-2\left(1-\alpha_{r}\right)\left(t_{d}-t_{r}\right)\right] .
\end{aligned}
$$

When $T_{d}>T_{r}$ and $t_{d}>t_{r}$, we can obtain $\Pi_{r}^{D M}<\Pi_{r}^{M}$.

(iii)

$$
\begin{aligned}
\Pi_{d 1}^{D M}-\Pi_{d 1}^{M} & =\frac{1}{8\left(\alpha_{r}-\alpha_{d}\right)}\left(1-\alpha_{r}\right)\left(T_{d}-T_{r}\right)\left(T_{r}+\alpha_{d}-2 \alpha_{r}-t_{d}+2 t_{r}+\alpha_{d} T_{d}-\alpha_{r} T_{d}-\alpha_{r} T_{r}+\alpha_{d} t_{d}-2 \alpha_{r} t_{r}\right) \\
& <\frac{1}{8\left(\alpha_{r}-\alpha_{d}\right)}\left(1-\alpha_{r}\right)\left(T_{d}-T_{r}\right)\left(T_{r}-\alpha_{r}+t_{d}+2 t_{r}-\alpha_{r} T_{r}+\alpha_{d} t_{d}-2 \alpha_{r} t_{r}\right) \\
& <\frac{1}{8\left(\alpha_{r}-\alpha_{d}\right)}\left(1-\alpha_{r}\right)\left(T_{d}-T_{r}\right)\left[\left(1-\alpha_{r}\right) T_{r}+2\left(1-\alpha_{r}\right) t_{r}-\left(1-\alpha_{r}\right) t_{d}-\alpha_{r}\right] \\
& <\frac{1}{8\left(\alpha_{r}-\alpha_{d}\right)}\left(1-\alpha_{r}\right)\left(T_{d}-T_{r}\right)\left[\left(1-\alpha_{r}\right)\left(T_{r}+t_{r}\right)-\alpha_{r}\right]
\end{aligned}
$$


When $T_{d}>T_{r}$ and $\alpha_{r}>\left(1-\alpha_{r}\right)\left(T_{r}+t_{r}\right)$, we can obtain $\Pi_{d 1}^{D M}<\Pi_{d 1}^{M}$.

(iv)

$$
\begin{aligned}
\Pi_{d 2}^{D M}-\Pi_{d 2}^{M}= & \frac{1}{8\left(\alpha_{r}-\alpha_{d}\right)}\left(1-\alpha_{r}\right)\left(T_{d}-T_{r}\right) \\
& \cdot\left[\alpha_{d}-\left(1-\alpha_{d}\right)\left(T_{d}+t_{d}\right)\right] .
\end{aligned}
$$

When $T_{d}>T_{r}$ and $\alpha_{d}>\left(1-\alpha_{d}\right)\left(T_{d}+t_{d}\right)$, we can obtain $D_{d}^{D M}>D_{d}^{M}, \Pi_{d 2}^{D M}>\Pi_{d 2}^{M}$.

Proof of Proposition 9.

For a given $w$, taking the second derivative of $\Pi_{r}^{O}$ with respect to $p$,

$\left(\mathrm{d}^{2} \prod_{r}^{O} / \mathrm{d}(p)^{2}\right)=-2 \alpha_{r}$. With $\quad\left(\mathrm{d}^{2} \prod_{r}^{N} / \mathrm{d}(p)^{2}\right)<0, \quad$ a unique optimal $p$ can be determined by the first-order derivative $\left(\partial \prod_{r}^{O} / \partial p_{r}\right)=0$.

By substituting the optimal $p$ into $\Pi_{d f}^{O}$ and the second derivative of $\Pi_{d}^{O}$ with respect to $w$, $\left(\mathrm{d}^{2} \prod_{d}^{O} / \mathrm{d}(w)^{2}\right)=-\left(\alpha_{r}-(\eta / 4)\right)$. We assume $\alpha_{r}>(\eta / 4)$; then $\left(\mathrm{d}^{2} \prod_{d}^{O} / \mathrm{d}(w)^{2}\right)<0$. Therefore, the unique optimal $w^{O}$ can be determined by the first-order partial derivatives $\left(\partial \prod_{d}^{O} / \partial w\right)=0$.

By substituting $w^{O}$ into $p$, the optimal $p^{O}$ can be obtained. Thus, Proposition 9 is proven.

\section{Data Availability}

The data used to support the findings of this study are included within the article.

\section{Conflicts of Interest}

The authors have no conflicts of interest to declare.

\section{Acknowledgments}

This project was funded by the National Natural Science Foundation of China (NSFC) (71531008 and 71771055), Natural Science Foundation of Anhui Province (KJ2019A0520), Horizontal Cooperation Project of Fuyang Municipal Government (XDHXPT201704), and Key Project of Youth Talent Foundation of Fuyang Normal University (RCXM201901).

\section{References}

[1] W. Li, J. Chen, G. Liang, and B. Chen, "Money-back guarantee and personalized pricing in a Stackelberg manufacturer's dual-channel supply chain," International Journal of Production Economics, vol. 197, pp. 84-98, 2018.

[2] S. Millward, "Apple arrives on Lazada," 2017, https://www. techinasia.com/apple-opens-store-lazada.

[3] B. Chen and J. Chen, "Compete in price or service? - a study of personalized pricing and money back guarantees," Journal of Retailing, vol. 93, no. 2, pp. 154-171, 2017.

[4] B. McWilliams, "Money-back guarantees: helping the lowquality retailer," Management Science, vol. 58, no. 8, pp. 1521-1524, 2012.
[5] B. McWilliams and E. Gerstner, "Offering low price guarantees to improve customer retention," Journal of Retailing, vol. 82, no. 2, pp. 105-113, 2006.

[6] Y. Akçay, T. Boyac1, and D. Zhang, "Selling with money-back guarantees: the impact on prices, quantities, and retail profitability," Production and Operations Management, vol. 22, no. 4, pp. 777-791, 2013.

[7] J. Heydari, T.-M. Choi, and S. Radkhah, "Pareto improving supply chain coordination under a money-back guarantee service program," Service Science, vol. 9, no. 2, pp. 91-105, 2017.

[8] T. Suwelack, J. Hogreve, and W. D. Hoyer, "Understanding money-back guarantees: cognitive, affective, and behavioral outcomes," Journal of Retailing, vol. 87, no. 4, pp. 462-478, 2011.

[9] M. A. Ülkü, L. C. Dailey, and H. M. Yayla-Küllü, "Serving fraudulent consumers? The impact of return policies on retailer's profitability," Service Science, vol. 5, no. 4, pp. 296-309, 2013.

[10] National Retail Federation, National Retail Federation Consumer Returns in the Retail Industry, National Retail Federation, Washington, DC, USA, 2015.

[11] C. Ratcliff, "How fashion ecommerce retailers can reduce online return," 2014, https://econsultancy.com/how-fashionecommerce-retailers-can-reduce-online-returns/.

[12] J. Mostard and R. Teunter, "The newsboy problem with resalable returns: a single period model and case study," European Journal of Operational Research, vol. 169, no. 1, pp. 81-96, 2006.

[13] J. Stock, T. Speh, and H. Shear, "Many happy (product) returns," Harvard Business Review, vol. 80, no. 7, p. 16, 2002.

[14] J. A. Petersen and V. Kumar, "Perceived risk, product returns, and optimal resource allocation: evidence from a field experiment," Journal of Marketing Research, vol. 52, no. 2, pp. 268-285, 2015.

[15] X. Su, "Consumer returns policies and supply chain performance," Manufacturing \& Service Operations Management, vol. 11, no. 4, pp. 595-612, 2009.

[16] L. Hsiao and Y.-J. Chen, "Retailer's rationale to refuse consumer returns in supply chains," Naval Research Logistics (NRL), vol. 62, no. 8, pp. 686-701, 2015.

[17] M. Ferguson, V. D. R. Guide, and G. C. Souza, "Supply chain coordination for false failure returns," Manufacturing \& Service Operations Management, vol. 8, no. 4, pp. 376-393, 2006.

[18] B. Chen and J. Chen, "When to introduce an online channel, and offer money back guarantees and personalized pricing?" European Journal of Operational Research, vol. 257, no. 2, pp. 614-624, 2017.

[19] W.-y. K. Chiang, D. Chhajed, and J. D. Hess, "Direct marketing, indirect profits: a strategic analysis of dual-channel supply-chain design," Management Science, vol. 49, no. 1, pp. 1-20, 2003.

[20] K. Cattani, W. Gilland, H. S. Heese, and J. J. Swaminathan, "Abstract boiling frogs: pricing strategies for a manufacturer adding a direct channel that competes with the traditional channel," Production and Operations Management, vol. 15, no. 1, pp. 40-56, 2006.

[21] N. Serguei and R. Nils, "Supply chain choice on the internet," Management Science, vol. 52, no. 6, pp. 844-864, 2006.

[22] S. Bandyopadhyay and A. A. Paul, "Equilibrium returns policies in the presence of supplier competition," Marketing Science, vol. 29, no. 5, pp. 846-857, 2010. 
[23] G. P. Cachon and A. G. Kök, "Competing manufacturers in a retail supply chain: on contractual form and coordination," Management Science, vol. 56, no. 3, pp. 571-589, 2010.

[24] H. Emmons and S. M. Gilbert, "Note. The role of returns policies in pricing and inventory decisions for catalogue goods," Management Science, vol. 44, no. 2, pp. 276-283, 1998.

[25] G. Iyer and J. M. Villas-Boas, "A bargaining theory of distribution channels," Journal of Marketing Research, vol. 40, no. 1, pp. 80-100, 2003.

[26] V. Padmanabhan and I. P. L. Png, "Manufacturer's return policies and retail competition," Marketing Science, vol. 16, no. 1, pp. 81-94, 1997.

[27] V. Padmanabhan and I. P. L. Png, "Reply to "do returns policies intensify retail competition?" Marketing Science, vol. 23, no. 4, pp. 614-618, 2004.

[28] B. A. Pasternack, "Optimal pricing and return policies for perishable commodities," Marketing Science, vol. 27, no. 1, pp. 133-140, 2008.

[29] H. Wang, "Do returns policies intensify retail competition?" Marketing Science, vol. 23, no. 4, pp. 611-613, 2004.

[30] S. Moorthy and K. Srinivasan, "Signaling quality with a money-back guarantee: the role of transaction costs," Marketing Science, vol. 14, no. 4, pp. 442-466, 1995.

[31] S. Davis, E. Gerstner, and M. Hagerty, "Money back guarantees in retailing matching products to consumer tastes," Journal of Retailing, vol. 71, no. 1, pp. 7-22, 1995.

[32] State Administration for Industry and Commerce, Interim Measures for the Return without Reasons of Commodities Purchased Online within Seven Days, State Administration for Industry and Commerce, Beijing, China, 2017.

[33] E. Ofek, Z. Katona, and M. Sarvary, "“Bricks and clicks": the impact of product returns on the strategies of multichannel retailers," Marketing Science, vol. 30, no. 1, pp. 42-60, 2011.

[34] F.-F. Tang and X. Xing, "Will the growth of multi-channel retailing diminish the pricing of efficiency of the web?" Journal of Retailing, vol. 77, no. 3, pp. 319-333, 2001.

[35] F. Gao and X. Su, "Omnichannel retail operations with buyonline-and-pick-up-in-store," Management Science, vol. 63, no. 8, pp. 2478-2492, 2017.

[36] P. Zhang, Y. He, and X. Zhao, "“Preorder-online, pickup-instore" strategy for a dual-channel retailer," Transportation Research Part E: Logistics and Transportation Review, vol. 122, pp. 27-47, 2019.

[37] S. Balasubramanian, "Mail versus mall: a strategic analysis of competition between direct marketers and conventional retailers," Marketing Science, vol. 17, no. 3, pp. 181-195, 1998.

[38] L. Hsiao and Y.-J. Chen, "Strategic motive of introducing internet channels in a supply chain," Production and Operations Management, vol. 23, no. 1, pp. 36-47, 2014.

[39] D. R. Bell, S. Gallia, and A. Moreno, "How to win in an omnichannel world," MIT Sloan Management Review, vol. 56, no. 1, p. 45, 2014.

[40] E. Brynjolfsson, Y. J. Hu, and M. S. Rahman, "Competing in the age of omni-channel retailing," MIT Sloan Management Review, vol. 54, no. 4, pp. 23-29, 2013.

[41] D. Rigby, "The future of shopping," Harvard Business Review, vol. 89, no. 12, pp. 65-76, 2011.

[42] S. Gallino and A. Moreno, "Integration of online and offline channels in retail: the impact of sharing reliable inventory availability information," Management Science, vol. 60, no. 6, pp. 1434-1451, 2014.

[43] S. Gallino, A. Moreno, and I. Stamatopoulos, "Channel integration, sales dispersion, and inventory management," Management Science, vol. 63, no. 9, pp. 2813-2831, 2017.
[44] Y. Xia, T. Xiao, and G. P. Zhang, "The impact of product returns and retailer's service investment on manufacturer's channel strategies," Decision Sciences, vol. 48, no. 5, pp. 918-955, 2017.

[45] G. Li, L. Li, S. P. Sethi, and X. Guan, "Return strategy and pricing in a dual-channel supply chain," International Journal of Production Economics, vol. 215, pp. 153-164, 2019.

[46] J. Cao, K. C. So, and S. Yin, "Impact of an "online-to-store" channel on demand allocation, pricing and profitability," European Journal of Operational Research, vol. 248, no. 1, pp. 234-245, 2016.

[47] A. Atasu and G. C. Souza, "How does product recovery affect quality choice?" Production and Operations Management, vol. 22, no. 4, pp. 991-1010, 2013.

[48] B. W. Jacobs and R. Subramanian, "Sharing responsibility for product recovery across the supply chain," Production and Operations Management, vol. 21, no. 1, pp. 85-100, 2012. 